\title{
INCORPORACIÓN DE LA ENERGÍA SOLAR EN LAS TECNOLOGÍAS DEL AGUA: DESALACIÓN SOLAR PARA LA PROVISIÓN DE AGUA EN ZONAS REMOTAS
}

\section{INCORPORATON OF SOLAR ENERGY IN WATER TECHNOLOGIES: SOLAR DESALINATION FOR THE PROVISION OF WATER IN REMOTE AREAS}

\author{
Julián Blanco Gálvez ${ }^{1}$, Diego Alarcón Padilla²
}

\begin{abstract}
RESUMEN
El siglo XX ha traído un desarrollo sin precedentes en la historia de la humanidad con avances impresionantes en todas las disciplinas de la ciencia y de la técnica. Sin embargo dichos avances no han sido algo gratuito, sino que han tenido un precio que no sería descabellado considerar que, bajo determinados prismas, ha sido excesivo. Durante los últimos 100 años, la población humana en la Tierra se ha multiplicado por un factor de 4 (pasando de 1.600 millones de personas en 1.900 a los más de 6.000 millones de la actualidad). Sin embargo el consumo de agua se ha multiplicado por 9 en el mismo periodo y el consumo de energía por 16, y ello con una degradación asociada del medio ambiente y los recursos naturales, en general, muy significativa.
\end{abstract}

Palabras clave.- Energía solar, Desalación solar.

\begin{abstract}
The XX century has brought an unprecedented development in the history of humanity with impressive advances in all disciplines of science and technology. But these progresses have not been something free, but have had a price that would not be unreasonable to consider that, under certain prisms, has been excessive. During the past 100 years, the human population on earth has increased by a factor of 4 (from 1600 million in 1900 to over 6,000 million today). However water consumption has increased by 9 in the same period and power consumption by 16, and therefore associated with a degradation of the environment and natural resources in general, very significant.
\end{abstract}

Keywords.- Solar energy, Desalination solar.

\section{INTRODUCCION}

El agua y la energía, conjuntamente con el aire como elemento que permite la respiración, son los 3 elementos fundamentales de los que depende la existencia tanto de nuestra vida como de nuestra civilización (obviamente, una está ligada a la otra). Existe un claro consenso en la actualidad que el impacto que ésta sobrexplotación de los recursos está teniendo sobre el frágil ecosistema del planeta, nos está llevando al límite de las posibilidades de sostenibilidad (si no se ha sobrepasado ya) que este puede ofrecer. Es preciso por lo tanto cambiar este desarrollo, que claramente ha sido y está siendo, insostenible, por otro que sí lo sea. En este sentido, debemos de entender "desarrollo sostenible" como aquel que es capaz de satisfacer nuestras necesidades sin comprometer las necesidades de las generaciones futuras.

Para poder romper el círculo vicioso actual, a nuestro entender, son precisos (además de otros) tres ingredientes fundamentales:

\footnotetext{
${ }^{1}$ Plataforma Solar de Almería, España, ${ }^{2}$ Plataforma Solar de Almería, España.
} 
1. Nuevas ideas que sean (o puedan ser) asumidas por una mayoría de la población

2. Tecnologías innovadoras más eficaces, respetuosas con el medio ambiente
3. Una voluntad política decidida para la implementación de las 2 anteriores.
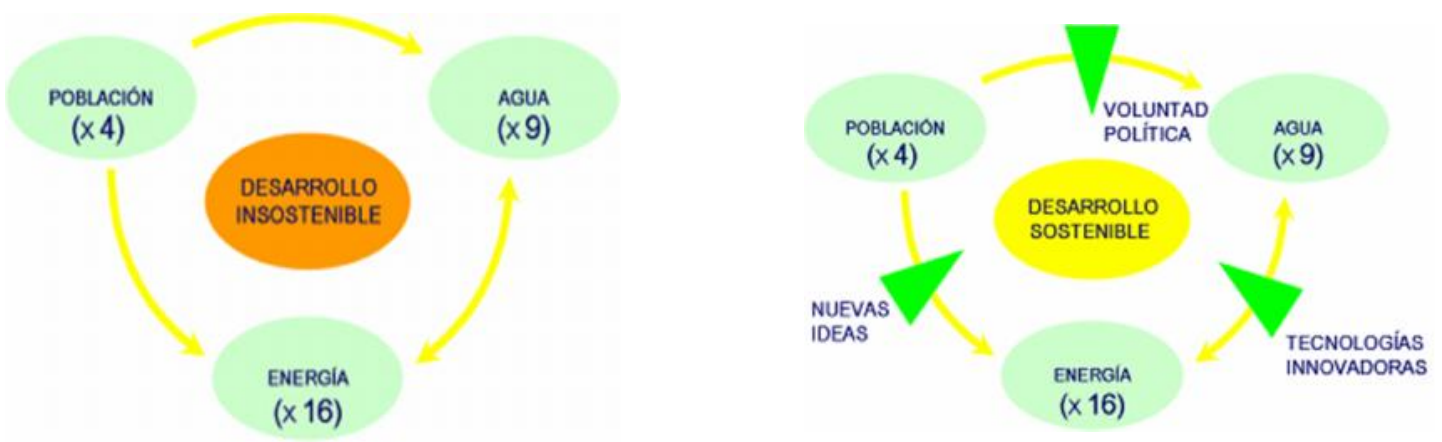

Fig. 1 Esquema de desarrollo en el siglo XX (izqda) y el que se propone para el XXI (dcha).

En este contexto, las energías renovables en general, y la energía solar en particular, pueden y deben jugar un papel relevante para ayudar a conseguir este objetivo de desarrollo sostenible.

Esto es algo no sólo deseable, sino también inevitable, ya que las opciones disponibles no son muchas y los problemas que se vislumbran en el horizonte son abrumadores.

Este documento pretende dar una visión global de dichos problemas y de las soluciones dirigidas a resolver una serie de problemáticas medioambientales centradas en los elementos fundamentales indicados anteriormente (agua y energía), utilizando para ello la energía solar como fuente primaria de energía.

\section{SITUACIÓN DE LAS ENERGÍAS CONVENCIONALES}

El petróleo ha sido durante todo el siglo XX, y lo sigue siendo en la actualidad, nuestra principal fuente de suministro energético (Figura 2), no siendo exagerado el afirmar que todo el modelo de vida "occidental" gira en torno a este elemento. Baste con considerar que todo el proceso de extracción, transporte y transformación del petróleo constituye la primera actividad mundial en términos económicos. La segunda es la industria de la automoción, estrechamente relacionada con la anterior. La dependencia del petróleo de nuestra sociedad queda patente con el siguiente dato: en 1880 la producción mundial, localizada casi por completo en Estados Unidos, era inferior al millón de toneladas. Hoy, la producción supera los 3.500 millones de toneladas 


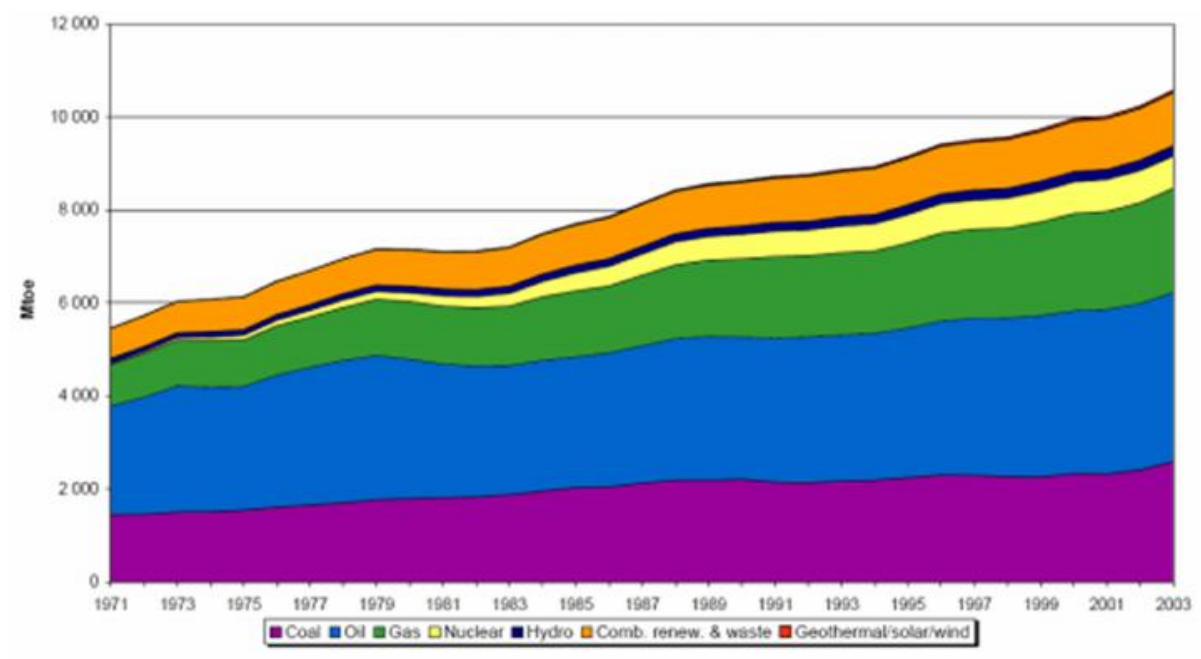

Fig. 2 Evolución de la "cesta" energética durante desde 1971 hasta 2003 para el suministro primario de energía. Unidades en millones de toneladas equivalentes de petróleo (MTep). Fuente: Agencia Internacional de la Energía.

Parece evidente que nos encontramos no ya ante una crisis más del petróleo, sino ante el fin de una era dominada por la tecnología basada en el uso del mismo. En el mundo cada día se consume una energía equivalente a 210 millones de barriles de petróleo. El $75 \%$ de estas necesidades energéticas se cubren con la quema de combustibles fósiles (petróleo, gas natural y carbón), responsables además de la contaminación atmosférica causante del cambio climático. EE.UU. produce sólo el 12\% de la producción mundial de petróleo pero consume el $25 \%$ y es el responsable directo de la cuarta parte de las emisiones de $\mathrm{CO}_{2}$ con tan sólo el $4 \%$ de la población. ¿Cuánto petróleo queda en el mundo? La respuesta no es inmediata ya que depende de si se es un "optimista" o un "pesimista" al respecto. Para un "pesimista", según diversos estudios, en 2002 quedaban en el mundo entre 990.000 millones y 1,1 billones de barriles de crudo por extraer.

Esto significa que al ritmo actual de consumo mundial estas reservas se agotarían alrededor del año 2050, fecha que podría ser más cercana si el consumo de energía aumentara, como se prevé que ocurra por parte de los países en vías de desarrollo. Aquí se debe entender por "agotamiento" el que el petróleo alcanzase un coste tal que lo hiciese económicamente inviable (Fig. 3). Con el ritmo actual de producción, EE.UU. tiene crudo para 11 años, pero si tuviera que producir todo lo que consume sólo tendría para 4.

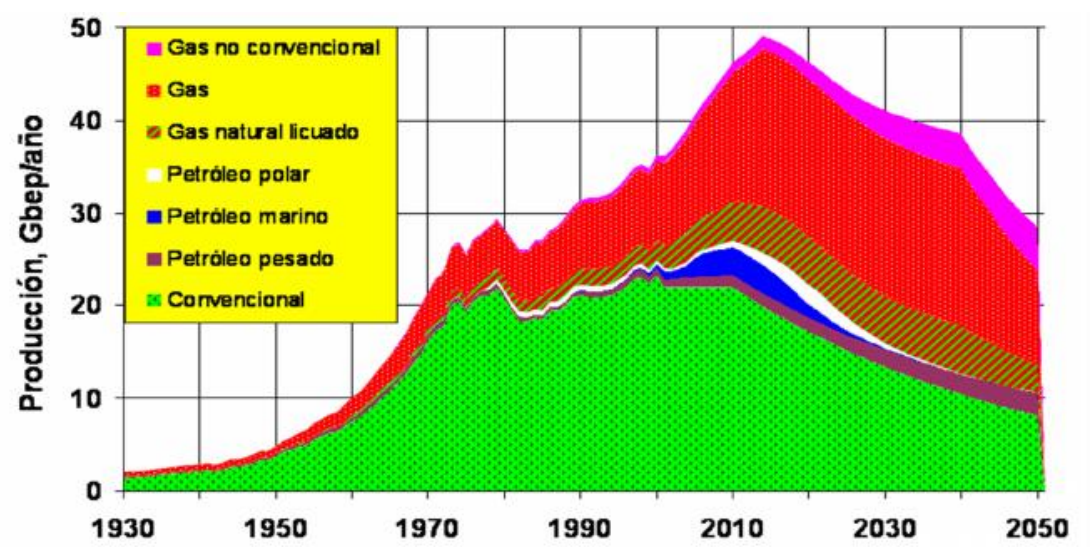

Fig. 3 Evolución de producción de combustibles fósiles (en giga-barriles equivalentes de petróleo por año) desde 1930 y estimación "pesimista" de evolución de dicha producción. 
Para un "optimista", esta fecha se podría retrasar de una forma importante con nuevos descubrimientos de yacimientos (aunque aquí no queda mucho más por explorar), con la extracción en lugares considerados inviables bien técnica o económicamente hasta hace poco (por ejemplo, con perforaciones marinas a más de $1000 \mathrm{~m}$ de profundidad) y sobre todo, si se mejoran los porcentajes de extracción de los pozos. En este sentido, los avances técnicos han permitido que los porcentajes iniciales del 15 al 20\% de petróleo que se podía extraer del total que había en un yacimiento, hoy estén entre 35 a 40\%. Ir más allá, en la actualidad, requiere unos costes energéticos superiores a los que proporciona el petróleo extraído. Sin embargo una mejora, aunque sólo sea de 1 punto en este porcentaje incrementaría de forma importante las reservas "existentes". Sin embargo, el principal problema no es cuando se va a "acabar" el petróleo, sino cuando se producirá el denominado "oil peak": momento en el cual la demanda será claramente superior a la capacidad de producción (limitada por las condiciones de presión internas de los yacimientos. Dado que la demanda, en los últimos 10 años ha ido subiendo de forma incesante debido a que países como China (con un crecimiento sostenido entre el 8 y el $10 \%$ durante muchos años) e India se han incorporado a club de grandes consumidores de energía, este momento se va a alcanzar mucho antes. Existen discrepancias en torno a cuando se producirá este fenómeno, que van desde que ya se ha producido, hasta dar la fecha entre 2030 a 2035.

En cualquier caso, parece que "la fiesta" toca a su fin. Las tres zonas que concentran la producción mundial son Oriente Medio, la antigua Unión Soviética y Estados Unidos; en torno al $70 \%$ del crudo del mundo procede de ellas. Sin duda, la región más importante es la de Oriente Medio, que reúne las condiciones óptimas para la explotación de este hidrocarburo: abundancia de domos salinos que crean grandes bolsas de petróleo, una inmejorable ubicación geográfica -su situación costera- y una orográfica que facilita la construcción de canalizaciones que permiten el transporte hasta los puertos del crudo, para ser distribuido desde allí. Arabia Saudí, con casi el $12 \%$ de la producción total, es el mayor productor del mundo.

Tabla 1. Reservas de petróleo mundiales (2001), en miles de millones de barriles [IEA].

\begin{tabular}{lrll}
\hline Arabia Saudí, & 265,3 & China & 46,6 \\
\hline Irak & 115,0 & Libia & 30,0 \\
Kuwait & 98,0 & México & 26,9 \\
Irán & 96,4 & Nigeria & 24,1 \\
Emiratos Arabes Unidos & 62,8 & Estados Unidos & 22,0 \\
Rusia & 54,3 & Argelia & 12,7 \\
Venezuela & 47,6 & Noruega & 10,1 \\
\hline
\end{tabular}

Tabla 2. Ranking de compañías petroleras (2000), en miles de barriles/día [IEA].

\begin{tabular}{llll}
\hline 1. & Gazprom & (Rusia) & 9.606 \\
\hline 2 & Saudi Aramco & (Arabia Saudí) & 8.613 \\
3 & NIOC & (Irán) & 4.509 \\
4 & Exxon Mobil & (EE.UU), & 4.406 \\
5 & Pemex & (México), & 4.169 \\
6 & Royal Dutch/Shell & (Holanda) & 3.685 \\
7 & PDVSA & (Venezuela), & 3.640 \\
8 & BP & (Reino Unido), & 3.107 \\
9 & Sonatrach & (Argelia), & 2.788 \\
10 & NOC & (Iraq) & 2.583 \\
$\ldots$ & & & \\
30 & Repsol YPF & (España) & 675 \\
\hline
\end{tabular}




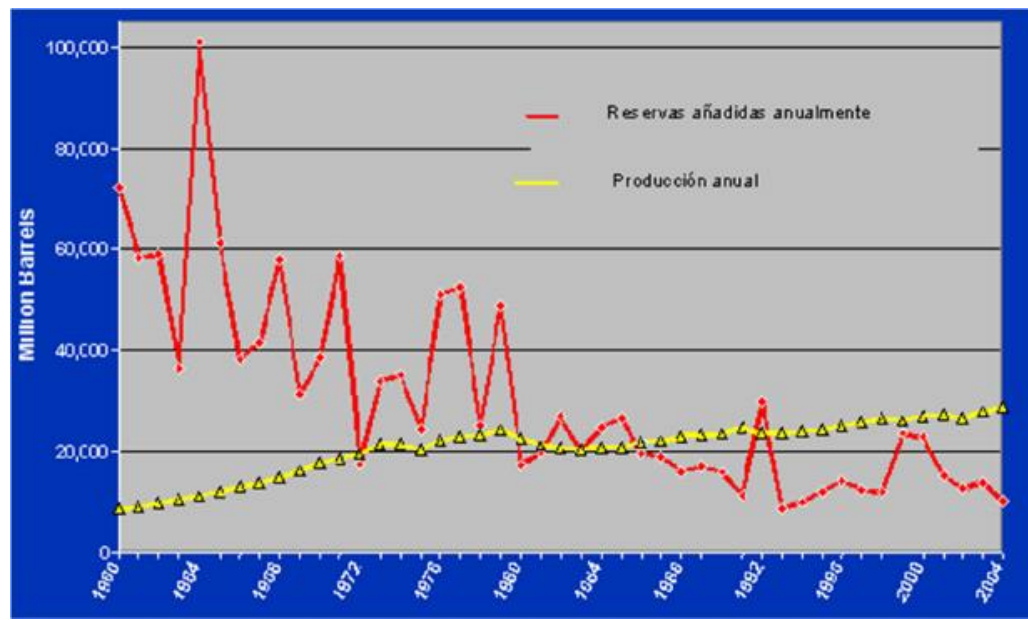

Fig. 4 Evolución de incremento anual de reservas y producción mundial de petróleo.

Por lo tanto las fuentes "convencionales" de energía con un potencial realmente relevante para cubrir las necesidades energéticas durante el siglo XXI que nos quedan son dos: la nuclear y el carbón. En ambos casos todavía no disponemos de tecnologías que se puedan calificar de sostenibles. En el caso de la energía nuclear, el proceso disponible está basado en la energía de fisión, que usa como combustible uranio enriquecido. Se han propuesto mejoras apreciables al diseño clásico en lo que respecta a la seguridad de funcionamiento, pero apenas en lo que respecta a los residuos, ni al coste. Los diseños avanzados las llamadas centrales de cuarta generación- están todavía muy lejos de una explotación industrial. Y la tecnología nuclear actual sólo sería de transición: no hay combustible nuclear suficiente en el largo plazo (limitación de las reservas de uranio fisionable), su uso no puede generalizarse a todos los países, dadas las economías de escala y las capacidades tecnológicas a las que obliga, y hay partes del ciclo del combustible que solamente unos pocos países detentan y son declaradas no transferibles ni desarrollables por otros. La conclusión es que la tecnología actual no es sostenible; es ineficiente e incumple el criterio básico de no gravar a las generaciones venideras, que tienen que convivir con los residuos durante cientos de miles de años.

Por otra parte, el uso masivo del carbón tiene asociado el agravamiento del importante problema de generación masiva de $\mathrm{CO}_{2}$, afectando a la problemática del cambio climático como resultado directo de su incremento en la atmósfera (producto de la quema de combustibles fósiles). La relación entre la concentración de $\mathrm{CO}_{2}$ y el calentamiento global parece que es algo ya claramente demostrado y asumido por la comunidad científica (Fig. 5). 


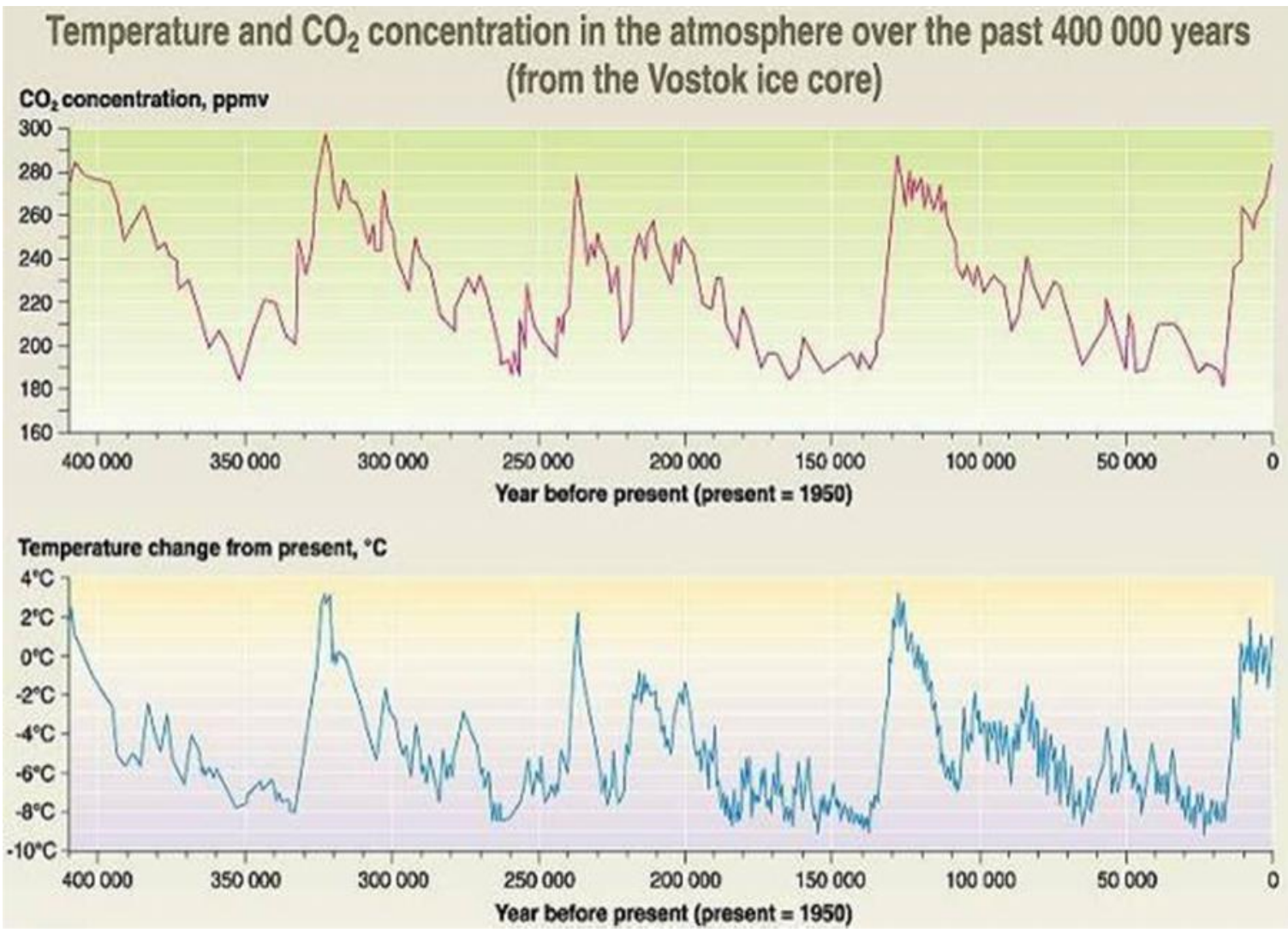

Fig. 5 Variación de $\mathrm{CO}_{2}$ en la atmósfera y cambio de temperatura durante los últimos 420.000 años [J.R. Petit et. al, 1999].

\section{POTENCIAL DE LAS ENERGÍAS RENOVABLES}

Las tecnologías de las fuentes renovables -para producir electricidad, generar calor o mover el transporte- están cada vez más contrastadas, aunque hasta la fecha sólo algunas han empezado a abrirse hueco en el mercado de forma clara. Aunque su contribución actual es pequeña (Fig. 6), su potencial es muy alto y, además de las ventajas ambientales, no hay que olvidar la posibilidad de generación de riqueza autóctona que poseen estas energías (eólica, solar fotovoltaica, solar térmica, biomasa, biocarburantes, etc).

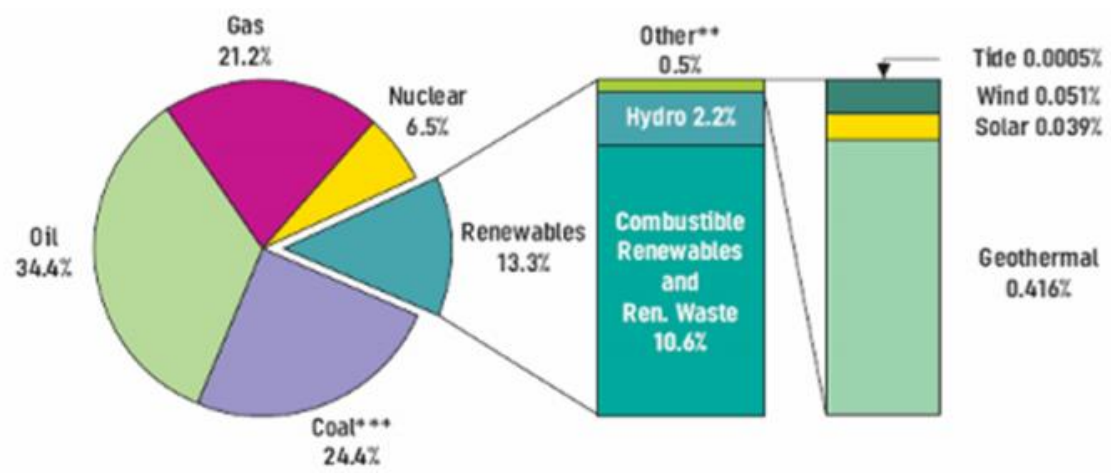

Fig. 6 Distribución de suministro primario de energía total mundial año 2003. [IEA] ** Geotérmica, solar, eólica, mareas/olas/corrientes marinas / *** Incluye residuos no renovables 
Este potencial, en el caso sobre todo de las energías geotérmica, solar y eólica, es especialmente elevado según puede observarse en la Fig. 7. Durante los últimos 33 años aunque el crecimiento global de las energías renovables ha sido similar al crecimiento de la producción de energía primaria, el crecimiento de las energías renovables indicadas anteriormente ha sido muy superior.

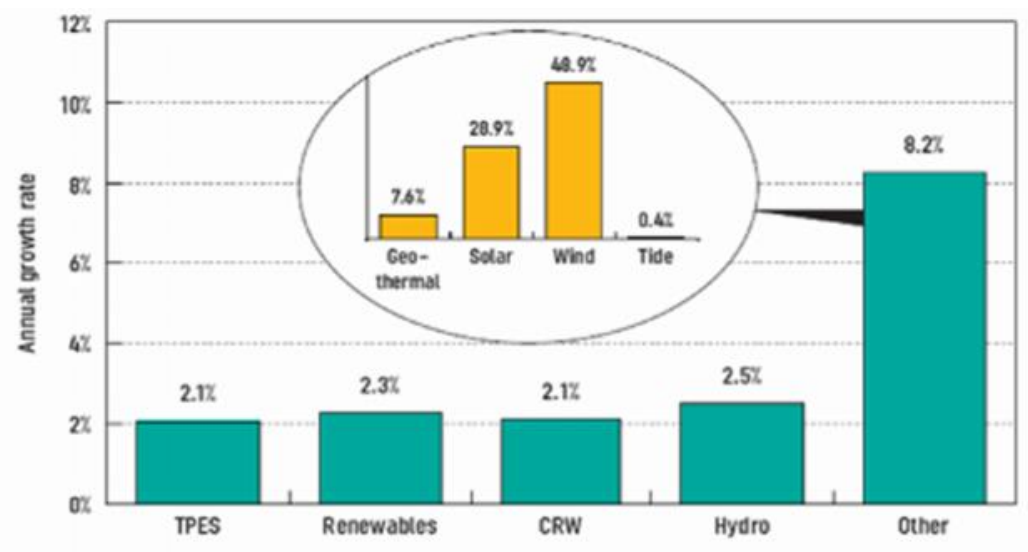

Fig. 7 Crecimiento anual de energías renovables, de 1971 a 2003. TPES: Total Primary Energy Supply, CRW: Combustible Renewable and Waste [Fuente: IEA, 2003].

Otros datos que demuestra que las renovables son el sector energético que más está creciendo los tenemos en que, entre 1993 y el 2003, la potencia eólica instalada se incrementó en todo el mundo un $30 \%$, y la de las plantas fotovoltaicas, un $21,5 \%$, porcentajes muy superiores a los del gas natural $(2,2 \%)$, petróleo $(1,3 \%)$, carbón $(1 \%)$ o nuclear $(0,6 \%)$. El potencial estimado de las distintas energías renovables aparece indicado en la Tabla 3.

Tabla 3. Potencial estimado anual de las distintas fuentes de energía renovables ( 1 TW equivale a un consumo sostenido de $10^{12} \mathrm{~W}$; este valor durante un año $\left.=8760 \mathrm{TWh}\right)$.

\begin{tabular}{|c|c|c|}
\hline Geotérmica & $12 \mathrm{TW}$ & Total estimado factible \\
\hline as/Olas & $2 \mathrm{TW}$ & Valor estimado bruto total \\
\hline Eólica & $\begin{array}{l}2-4 \mathrm{TW} \\
\text { (practico) }\end{array}$ & $\begin{array}{l}\text { Potencial extraíble. Potencial teórico total: } 55 \text { TW, } \\
\text { considerando el uso del } 5 \% \text { del terreno }\end{array}$ \\
\hline Biomasa & $5-7 \mathrm{TW}$ & $\begin{array}{l}\text { Considerando el uso del } 50 \% \text { de toda la tierra } \\
\text { cultivable }\end{array}$ \\
\hline Hidráulica & $\begin{array}{l}4,6 \mathrm{TW} \\
\text { (bruto) }\end{array}$ & $\begin{array}{l}\text { 1,6 TW (técnicamente factible) / 0,9 TW } \\
\text { (económicamente factible) / 0,6 TW (instalada) }\end{array}$ \\
\hline 14 & $\begin{array}{l}600 \mathrm{TW} \\
\text { (práctico) }\end{array}$ & $\begin{array}{l}\text { Valor práctico estimado. Potencial teórico total: } \\
12.000 \mathrm{TW}\end{array}$ \\
\hline
\end{tabular}

Para poder ubicar la magnitud de las cifras indicadas en la Tabla 3, hay que indicar que el consumo total de energía de la humanidad en el año 2003 fue de 10.723 MTep (millones de toneladas equivalentes de petróleo), equivalente a 14,28 TW (Fig. 2, IEA), siendo las previsiones de llegar a los 25-30 TW para el año 2050 y a los 40-
50 TW para el 2100 [Hoffer et al., 1998]. En 1999, el consumo global de energía en Estados Unidos equivalía a 3,3 TW [Denis Hayes, 2005]. El factor más crítico para este aumento de consumo es tanto el incremento de la actividad económica como, sobre todo, el de la población mundial (Figura 8). 


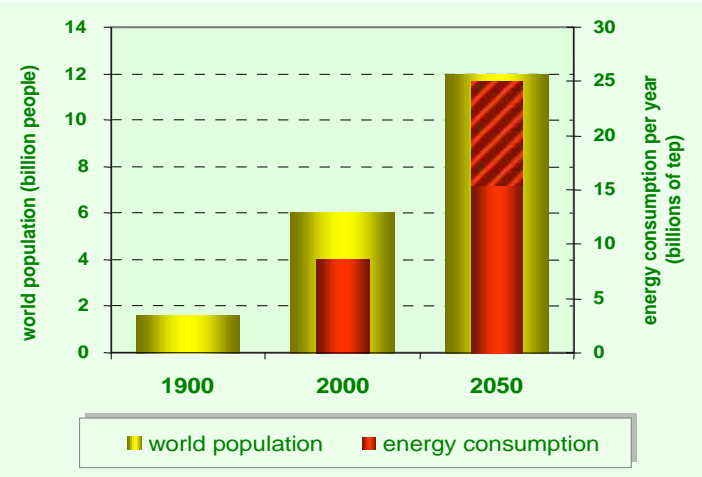

Fig. 8 Evolución de la población mundial y consumo de energía.

Entre las distintas energías renovables existentes, la que ha tenido un mayor despegue en los últimos 10 años ha sido claramente la energía eólica, que ha venido doblando la capacidad total instalada cada 3 años (Figura 9), con un crecimiento aún mayor en los últimos años. Esta tecnología puede considerarse competitiva con relación a las tecnologías más convencionales, pues, desde principios de los ochenta su coste de producción se ha reducido a una décima parte. En el año 2005 la potencia eólica total instalada era de 59.322 MW, con un crecimiento del $25 \%$ sobre 2004; si se mantienen los ritmos de crecimiento actuales, hacia el año 2020 el mundo podría dispondría de unos 2,6 millones de MW eólicos instalados. Sin embargo, como se ha indicado anteriormente, es en el campo de la energía solar (térmica/fotovoltaica) donde se tienen los mayores potenciales para su utilización y aprovechamiento (sin tener en cuenta que, en el fondo, las energías eólicas, biomasa, olas, etc, no son sino distintas manifestaciones de la energía solar).

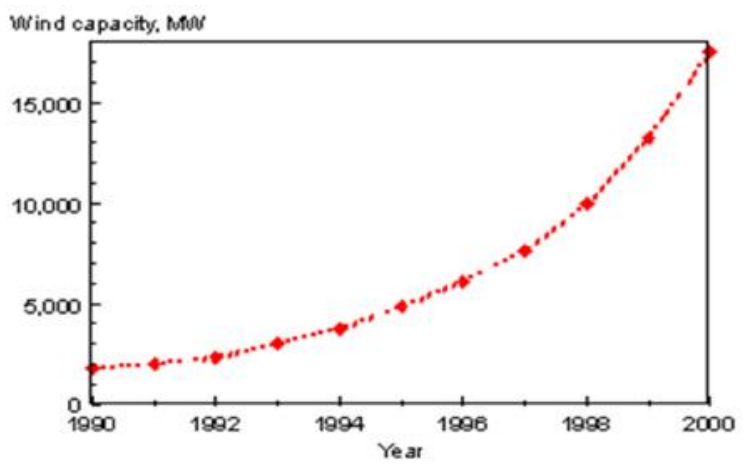

Fig. 9 Crecimiento de la capacidad mundial

\section{instalada de energía eólica.}

Existen una gran cantidad de localizaciones donde la irradiación solar media anual puede considerarse suficientemente elevada para considerar práctico y factible su aprovechamiento mediante procesos tecnológicos. Aproximadamente una tercera parte de la superficie del globo recibe una radiación anual superior a los $1.500 \mathrm{kWh} / \mathrm{m}^{2}$, con valores máximos incluso superiores a los $2.200 \mathrm{kWh} / \mathrm{m}^{2}$.

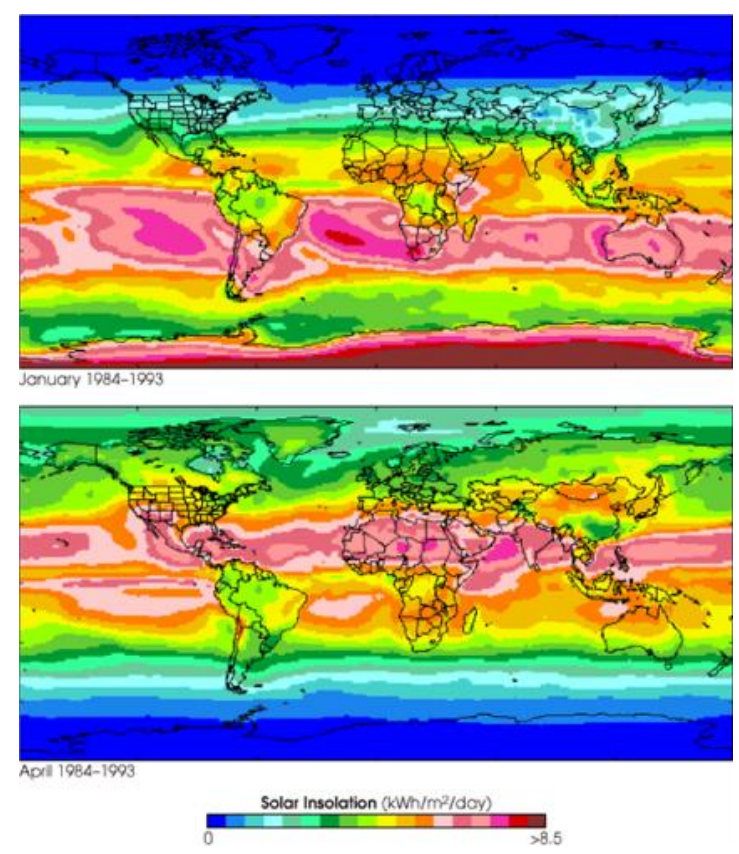

Fig. 10 Irradiancia solar media (años: 1984 a 1994) Fuente: Earth Observatory, NASA.

Estos valores nos permiten realizar, de forma sencilla, los siguientes cálculos orientativos que nos permitirán valorar el potencial que puede tener esta energía:

- Considerando el valor indicado anteriormente (año 2003) de 14,28 TW de consumo total de energía, equivalentes a $125.100 \mathrm{TWh}=125.100 \times 10^{9} \mathrm{kWh}$.

- Si consideramos una irradiancia media (entre la franja anteriormente considerada) de $1.800 \mathrm{kWh} / \mathrm{m}^{2}$, se obtiene que $1 \mathrm{~km}^{2}$ $\left(10^{6} \mathrm{~m}^{2}\right)$ recibe $1.800 \times 10^{6} \mathrm{kWh}$ (energía total anual).

- Dividiendo el primer número entre el segundo se obtiene que una superficie total 
de $69.500 \mathrm{~km}^{2}$ podría captar el equivalente de esa energía consumida en el año 2003

- En el caso de la energía solar térmica (de concentración), esta superficie habría que multiplicarla por 3 factores:

a) efíciencia de captación de los dispositivos tecnológicos que se utilicen para trasladar esta energía a un fluido (entre 0,6 y 0,75 )

b) Eficiencia del proceso o ciclo que se utilice para transformar ese fluido caliente en energía a través de una máquina térmica (entre 0,35 y 0,48 mediante la utilización de ciclos combinados)

c) Factor de ocupación del terreno con los equipos captadores (entre $0,5$ y 0,6$)$

- En el caso de la energía fotovoltaica la eficiencia global de captación (equivalente a los factores a y b anteriores) de las células actuales es del orden de 0,12

- En el caso de la energía solar térmica, considerando unos factores realistas (con la tecnología contrastada existente en la actualidad): $a=0,7 ; b=0,4$ y $c=0,55$, se obtiene una superficie total de 451.300 $\mathrm{km}^{2}$ (a efectos comparativos, España tiene una superficie total de $505.000 \mathrm{~km}^{2}$ ).

Obviamente, la extensión puede parecer exagerada, pero si tenemos en cuenta que la superficie total de desiertos es del orden de $12.632 .000 \mathrm{~km}^{2}$ (aproximadamente, el $12 \%$ de la superficie continental del planeta), solamente utilizando la superficie de los mismos podríamos cubrir 28 veces nuestras necesidades actuales de energía.

\section{PROBLEMÁTICA DEL AGUA BINOMIO AGUA/ENERGÍA}

"El consumo mundial de agua dulce se multiplicó por seis entre 1900 y 1995 - más del doble que la tasa de crecimiento de la población. En torno a un tercio de la población mundial vive en la actualidad en países que sufren "estrés hídrico" esto es, que su consumo supera en un $10 \%$ el valor de la capacidad de sus recursos hídricos renovables. De continuar esta tendencia, dos de cada tres personas en la Tierra se encontrarán en esa misma situación hacia el año 2025". Kofi Annan, en We The Peoples, 2000.

Con ser preocupante la problemática actual de la energía, mucho más lo es la relativa al agua. La disponibilidad de agua potable es claramente una condición clave tanto para la subsistencia como para el desarrollo económico de la humanidad. También, la gestión sostenible de esta fuente puede ser considerada como una medida crítica para el estudio de la sostenibilidad o sustentabilidad de una comunidad global. Aunque las fuentes de agua potable en la Tierra podrían ser suficientes para garantizar un desarrollo racional de nuestra sociedad en todo el planeta, el problema de la escasez de agua es un hecho patente debido, entre otras, a las siguientes tres razones fundamentales:

- En muchas zonas del globo no hay agua dulce en abundancia, ya que el agua no está distribuida equitativamente entre la población humana de la Tierra.

- Existe una clara sobreexplotación del agua. La explotación de las fuentes de agua por encima de límites racionales y sostenibles está trayendo como consecuencia una desertificación y empobrecimiento económico de distintas regiones del planeta.

- El desarrollo económico insostenible e incontrolado, que utiliza los ríos y lagos para descargar aguas conteniendo residuos químicos peligrosos y resistentes.

La Tierra contiene en torno a 1397 millones de $\mathrm{km}^{3}$ de agua, los cuales cubren aproximadamente el $70 \%$ de la superficie del planeta. De esta cantidad, aproximadamente el $97.5 \%$ se trata de agua salada con una concentración tal que resulta inservible para cualquier tipo de uso directo (humano, agrícola o industrial). El 2.5\% restante lo constituye agua dulce, de la cual el $69.6 \%$ se encuentra de manera permanente en forma de hielo o nieve en los polos o cumbres montañosas; el $30.1 \%$ se encuentra depositada en acuíferos y tan sólo el $0.30 \%$ se encuentra localizada en lagos y ríos, y por tanto es más fácilmente accesible desde el punto de vista técnico y económico (Figura 11). 


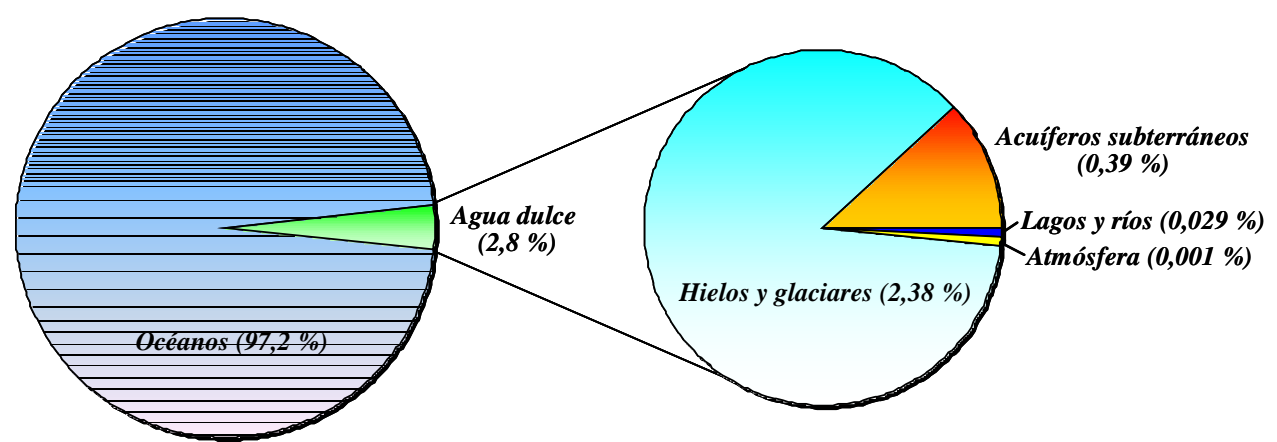

Fig. 11 Disponibilidad de agua en la tierra.

Tabla 4. Distribución terrestre de los recursos hídricos.

\begin{tabular}{lrrr}
\hline Recurso & Volumen $\left(\mathbf{k m}^{\mathbf{3}}\right)$ & $\begin{array}{c}\text { Porcentaje del agua } \\
\text { total }\end{array}$ & $\begin{array}{c}\text { Porcentaje de agua } \\
\text { dulce }\end{array}$ \\
\hline Vapor de agua & 12900 & 0.001 & 0.01 \\
Glaciares y nieves & 24064000 & 1.72 & 68.7 \\
permanentes & & & \\
Hielo terrestre & 300000 & 0.021 & 0.86 \\
Ríos & 2120 & 0.0002 & 0.006 \\
Lagos & 176400 & 0.013 & 0.26 \\
Pantanos y marismas & 11470 & 0.0008 & 0.03 \\
Humedad del suelo & 16500 & 0.0012 & 0.05 \\
Acuíferos & 10530000 & 0.75 & 30.1 \\
Litosfera & 23400000 & 1.68 & \\
Océanos & 1338000000 & 95.81 & \\
Total & $\mathbf{1 3 9 6 5 1 3 3 9 0}$ & & \\
\hline
\end{tabular}

Es posible establecer una clasificación de los diferentes tipos de agua en función de la concentración de sales que presentan. Una primera categoría sería el agua para la ingestión humana, las labores domésticas y cierto tipo de actividades industriales. Este tipo de agua presenta un intervalo de salinidad que va desde los 5 hasta los 1000 ppm. Un segunda categoría, que abarcaría el rango de salinidades entre 1000 y 3000 ppm, estaría destinada a su utilización en la agricultura y en los sistemas de refrigeración de determinadas industrias. Valores de salinidad entre 3000 y $10000 \mathrm{ppm}$ constituyen lo que se conoce como aguas salobres. Para valores de concentración superiores a $10000 \mathrm{ppm}$ estaríamos hablando de un agua de alta salinidad, entre la que se incluye el agua de mar, cuya concentración promedio se sitúa en torno a $34000 \mathrm{ppm}$, aunque este valor depende de las condiciones locales. Así, en la región del Golfo Pérsico, la concentración del agua de mar puede alcanzar valores máximos de $50000 \mathrm{ppm}$, mientras que en las costas de Florida (EEUU) se pueden alcanzar valores tan bajos como 30000 ppm. A la hora de determinar los recursos de agua dulce disponibles en una determinada región del planeta se distingue entre la componente de almacenamiento estático y el recurso hídrico renovable. El almacenamiento estático comprende el agua dulce con un periodo de renovación de varios años o incluso décadas, como es el caso de los grandes lagos, las aguas subterráneas, o los glaciares. La utilización intensiva de esta componente produciría inevitablemente una reducción del recurso con las consecuencias desfavorables que ello supondría, así como la alteración del equilibrio natural establecido a lo largo de los siglos. El recurso hídrico renovable comprende las aguas que son repuestas anualmente gracias al ciclo hidrológico natural de la Tierra y está constituido principalmente por la escorrentía 
de los ríos, y en menor medida por la componente renovable anual de la capa superficial de las aguas subterráneas que no terminan siendo desaguadas a los sistemas fluviales.

Un valor promedio a escala mundial de los recursos hídricos renovables se sitúa en torno a $42700 \mathrm{~km}^{3}$ por año, valor que presenta una gran variabilidad tanto desde un punto de vista espacial como temporal.
Como puede observarse en la Figura 12, seis países (Rusia, Brasil, Canadá, Estados Unidos, China e India) acaparan casi el 50\% de los recursos hídricos renovables totales, lo cual deja patente la mala distribución que de dicho recurso existe en el planeta.

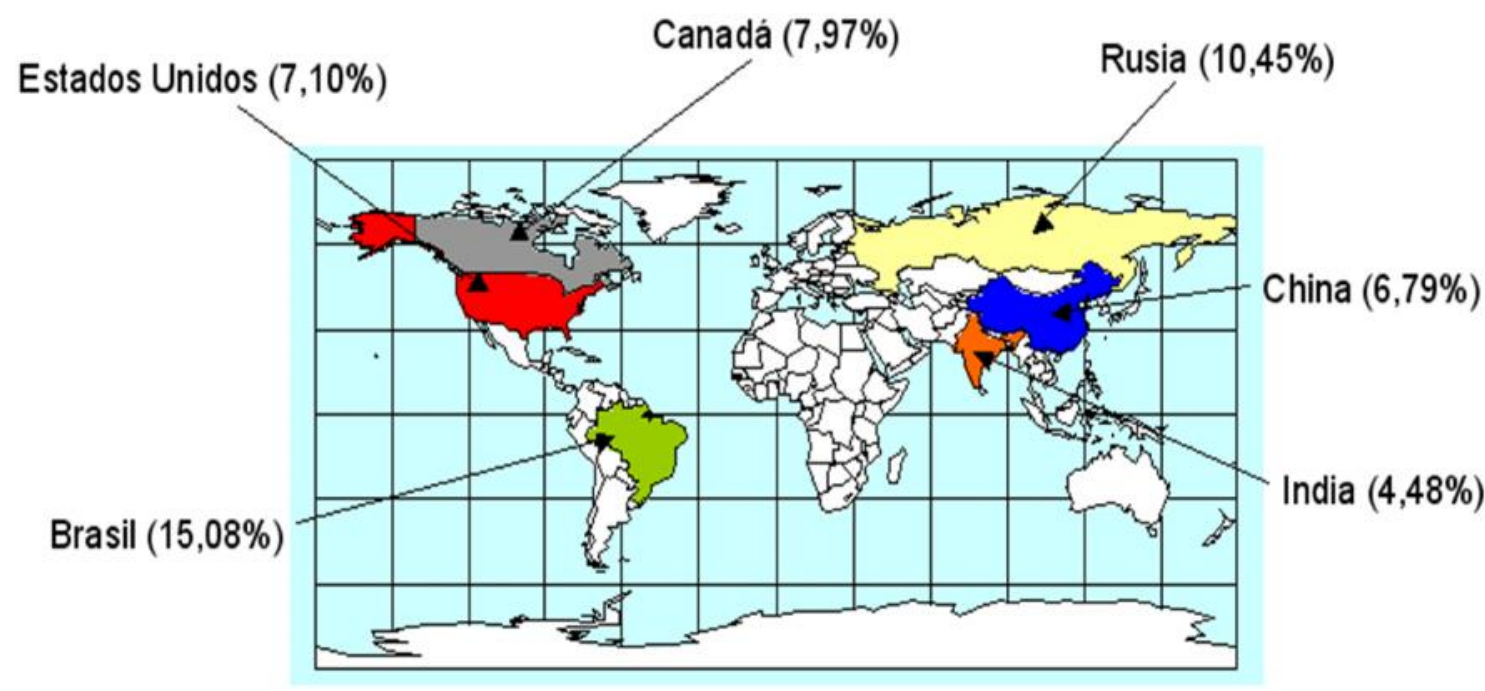

Fig. 12 Recursos hídricos renovables anuales de diferentes países (total mundial: $42700 \mathrm{~km}^{3} / a \tilde{n o}$ ).

Howard y Bartram establecen que un consumo promedio de 100-200 litros por habitante y día constituye un nivel de acceso óptimo por el cual se aseguran el consumo personal y la higiene necesarias para prevenir la transmisión de enfermedades infecciosas. La cantidad de agua mínima necesaria para beber por persona y día va desde los 2 litros en climas templados hasta los 4.5 litros para los habitantes de climas cálidos que tienen que llevar a cabo trabajos de tipo manual.

Algunos datos adicionales relevantes en torno al ciclo del agua en la Tierra son los siguientes:

- Cada año se evaporan 330 millones de $\mathrm{Hm}^{3}$ de agua de los océanos.

- Cada año se evaporan 63 millones de $\mathrm{Hm}^{3}$ de agua de los terrenos del planeta.

- Cada año caen a la tierra, en forma de precipitación, 100 millones de $\mathrm{Hm}^{3}$ de agua.
- La precipitación medida anual en el globo es de $660 \mathrm{~mm} / \mathrm{m}^{2}$.

En la actualidad, unos 1.000 millones de personas no tienen acceso directo a agua potable o lo tienen con dificultad; unos 2.400 millones carecen de agua para servicios sanitarios adecuados. Las previsiones de las Naciones Unidas son muy preocupantes ya que se espera que el problema se haga más agudo durante el siglo XXI (las cifras anteriores se espera se incrementen en 1.500 millones de personas más en total) debido básicamente, a los dos factores siguientes:

- El crecimiento imparable de la población (previsiones conservadoras preveen el doble de presente población mundial durante el siglo 21 y las más negativas el triple), lo que demandará un consumo cada vez mayor de agua potable.

- El efecto invernadero, que está acelerando la desertificación de muchas zonas alrededor 
del globo afectando tanto al ciclo hídrico como al cambio climático y reduciendo la media de precipitaciones esperadas en regiones ya desiertas o semi-desiertas.

En la Tabla 5 se muestra la clasificación de los diferentes niveles de acceso al recurso hídrico establecidos por la Organización Mundial de la Salud. En la actualidad, cerca de mil millones de personas carecen de acceso incluso al nivel de acceso básico, y 1600 millones sólo tienen acceso a un nivel básico de servicio.

Tabla 5. Nivel de servicio y cantidad de agua consumida.

\begin{tabular}{|c|c|c|c|}
\hline Nivel de servicio & Distancia / tiempo & $\begin{array}{c}\text { Volúmenes problables de } \\
\text { agua consumida }\end{array}$ & Necesidades cubiertas \\
\hline Sin acceso & $\begin{array}{l}\text { Más de } 1 \mathrm{~km} / \text { más } \\
\text { de } 30 \text { minutos (ida y } \\
\text { vuelta) }\end{array}$ & $\begin{array}{l}\text { Muy bajos (a menudo por } \\
\text { debajo de } 5 \text { litros por } \\
\text { persona y día) }\end{array}$ & $\begin{array}{l}\text { El consumo personal no está } \\
\text { asegurado. La higiene personal } \\
\text { está comprometida. El consumo } \\
\text { básico puede estar en peligro. }\end{array}$ \\
\hline Acceso básico & $\begin{array}{l}\text { Menos de } 1 \mathrm{~km} / \\
\text { menos de } 30 \text { minutos } \\
\text { (ida y vuelta) }\end{array}$ & $\begin{array}{l}\text { Baja probabilidad de } \\
\text { exceder los } 20 \text { litros por } \\
\text { persona y día }\end{array}$ & $\begin{array}{l}\text { El consumo personal debería } \\
\text { estar asegurado. La higiene } \\
\text { personal puede estar } \\
\text { comprometida. El lavado de } \\
\text { ropa se llevaría a cabo fuera del } \\
\text { ámbito de la vivienda. }\end{array}$ \\
\hline Acceso intermedio & $\begin{array}{l}\text { Suministro de agua } \\
\text { dentro de los } \\
\text { confines de la } \\
\text { vivienda mediante al } \\
\text { menos un grifo }\end{array}$ & $\begin{array}{l}\text { Promedio aproximado de } 50 \\
\text { litros por persona y día }\end{array}$ & $\begin{array}{l}\text { El consumo personal está } \\
\text { asegurado. La higiene personal } \\
\text { no debería estar comprometida. } \\
\text { El lavado de ropa se llevaría a } \\
\text { cabo probablemente dentro de } \\
\text { los límites de la vivienda. }\end{array}$ \\
\hline Acceso óptimo & $\begin{array}{l}\text { Suministro de agua a } \\
\text { través de múltiples } \\
\text { grifos distribuidos } \\
\text { por la vivienda }\end{array}$ & $\begin{array}{l}\text { Promedio de } 100-200 \text { litros } \\
\text { por persona y día }\end{array}$ & $\begin{array}{l}\text { El consumo personal está } \\
\text { asegurado. La higiene personal } \\
\text { no debería estar comprometida. } \\
\text { El lavado de ropa se llevaría a } \\
\text { cabo en el interior de la } \\
\text { vivienda. }\end{array}$ \\
\hline
\end{tabular}

El reciente Informe de las Naciones Unidas sobre el Desarrollo de los Recursos Hídricos en el Mundo alerta sobre una crisis sin precedentes en los años venideros como consecuencia de una creciente escasez de agua dulce por habitante en los países en vías de desarrollo.

Se prevé que en los próximos veinte años el suministro medio a escala mundial de agua por habitante disminuya en un tercio, apuntándose como causas principales de esta disminución del recurso hídrico el continuo crecimiento de la población mundial, los procesos de contaminación ambiental y el previsto cambio climático.

Para la segunda mitad del presente siglo se espera, en el peor escenario posible, que al menos siete mil millones de personas en 60 países del mundo se enfrenten con un problema de penuria hídrica; mientras que en el caso más favorable, dicha escasez afectará a dos mil millones de personas en 48 países, dependiendo de factores tales como la tasa de crecimiento de la población mundial y la implementación de políticas correctoras adecuadas. 

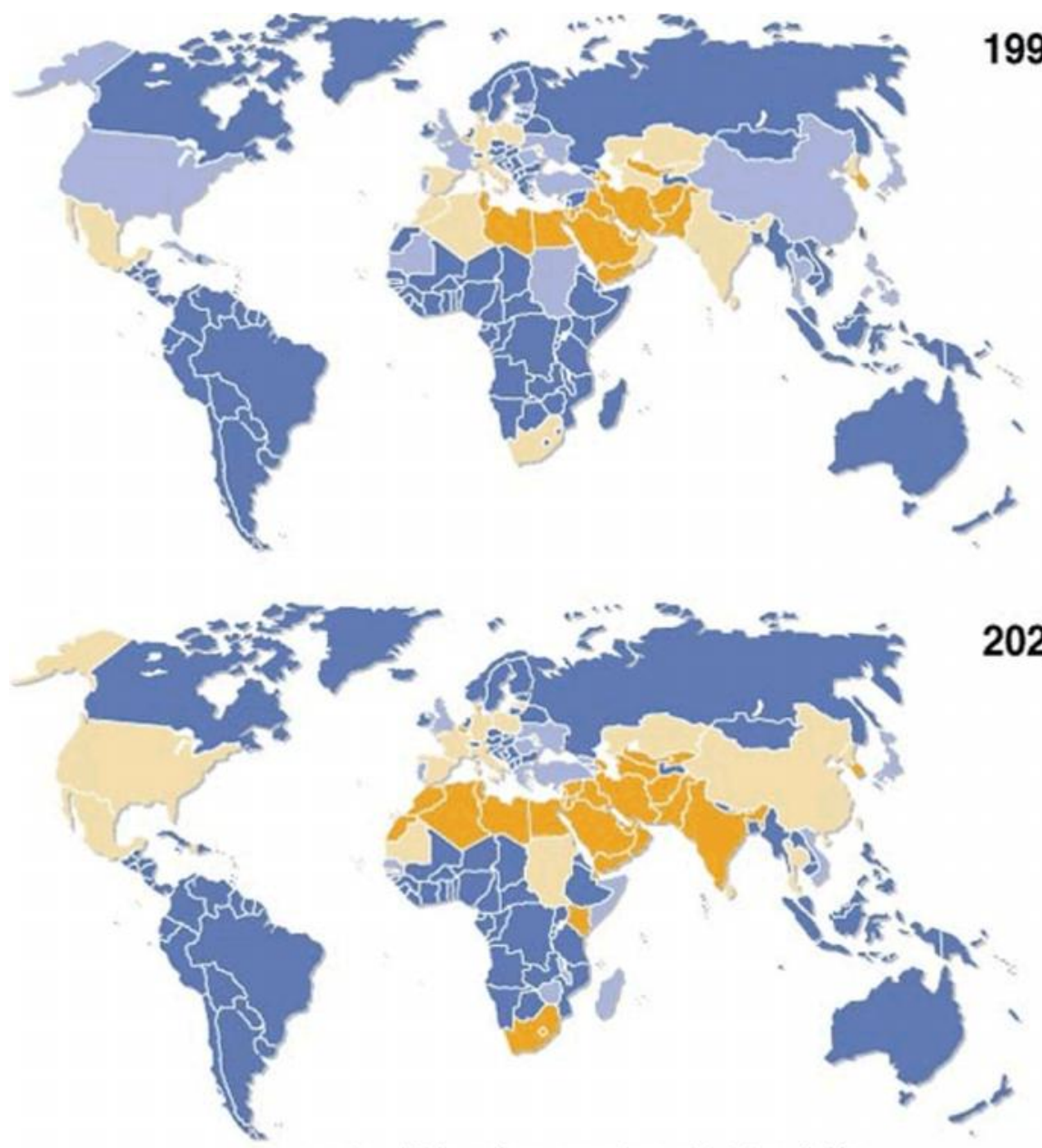

water withdrawal as percentage of total available

more than $40 \%$

$20 \%$ to $10 \%$

$40 \%$ to $20 \%$

less than $10 \%$

Fig. 13 Problemática global del agua en 1995 y estimada en 2025, considerando el porcentaje de agua abstraído con respecto al total disponible (Fuente: UNEP).

Las soluciones para paliar este problema de penuria hídrica pasan por el necesario ahorro por parte de todos los sectores consumidores, el fomento de las técnicas de depuración de las aguas superficiales y subterráneas, y la reutilización de aguas residuales. Sin embargo, existen zonas en el planeta (muy áridas o aisladas) que precisan de aportes externos para su desarrollo. En este caso, la desalación, y en especial la desalación de agua de mar, se postula como una de las principales alternativas para resolver el problema. No en vano, más del $70 \%$ de la población mundial vive en una franja de $70 \mathrm{~km}$ en torno a mares y océanos. Durante la segunda mitad del siglo XX, la desalación de agua de mar ha demostrado ser la única alternativa para muchas regiones del planeta tales como el Golfo Pérsico, el Mar Mediterráneo y el Caribe. Y hoy día, en los albores del siglo XXI, comienza a ser una alternativa económicamente viable para otras muchas partes del planeta debido, sobre todo, al encarecimiento de los métodos convencionales de obtención de agua potable.

Debido a ello, el desarrollo de técnicas, tecnologías y estrategias específicamente dirigidas al logro de una sostenibilidad completa en el tema del agua se convierte en una necesidad que va a resultar cada vez más acuciante. Dado que el binomio agua-energía está estrechamente 
relacionado (la existencia de uno de los dos factores permite resolver o paliar el otro), no tiene sentido abordar una de las problemáticas sin considerar seriamente la otra.

Es en este contexto, donde las energías renovables se presentan como unas de las herramientas más prometedoras para alcanzar soluciones viables y sostenibles. Entre ellas, la Energía Solar en particular, parece la más adecuada para solucionar los problemas del agua debido a la clara sinergia existente entre los dos tópicos. La importancia del problema de la escasez tanto de agua potable como de riego, se hace especialmente grave en los países en vías de desarrollo y del denominado tercer mundo, siendo además uno de los retos más importantes que tiene la humanidad para mejorar la calidad de vida, crecimiento y desarrollo económico de un tercio de la población del planeta (Figura 13).

Existen tres campos específicos de investigación a los que la Energía Solar puede aportar importantes avances científicos y tecnológicos para el logro de soluciones sostenibles para los problemas del agua $\mathrm{y}$ en los cuales el CIEMAT en general y la Plataforma Solar de Almería en particular están trabajando activamente:

- Desalación del agua de mar.

- Desinfección del agua (eliminación de elementos patógenos).

- Eliminación de contaminantes industriales peligrosos en el agua mediante procesos fotoquímicos.

Obviamente el primero (desalación solar), es el que puede tener un mayor impacto sobre la población en general, y muy especialmente en entornos remotos o aislados (Ver apéndice), la misma que ha sido extensamente desarrollada en la Plataforma Solar de Almería y pasamos a describir a continuación.

\section{EXPERIENCIAS EN DESALACIÓN DE AGUA DE MAR EN LA PLATAFORMA SOLAR DE ALMERÍA}

El CIEMAT (Centro de Investigaciones Energéticas, Medioambientales y Tecnológicas, España) y el DLR (Instituto Aerospacial Alemán, Alemania) decidieron en 1987 desarrollar un sistema avanzado de desalación basado en energía solar térmica. Para ello iniciaron el denominado Proyecto STD (Solar Thermal Desalination) cuyos trabajos se extendieron hasta el año 1994. Este proyecto estuvo dividido en dos fases, cada una de las cuales persiguió un objetivo específico:

- Fase I: estudiar la fiabilidad y viabilidad técnica de la incorporación de la energía solar térmica en los procesos de desalación de agua de mar.

- Fase II: implementación de mejoras específicas en el sistema instalado en la PSA durante la primera fase, con objeto de hacerlo más competitivo frente a los sistemas de desalación convencionales.

La Fase I del Proyecto STD comenzó en 1988 y su evaluación finalizó en 1990. Durante esta fase se implementó en la PSA un sistema de desalación solar compuesto por: i) Una planta de destilación multi-efecto con 14 efectos; ii) un campo de colectores solares cilindro-parabólicos; iii) un tanque de almacenamiento térmico termoclino.

Dichos subsistemas estuvieron interconectados tal como muestra la Figura 14. 


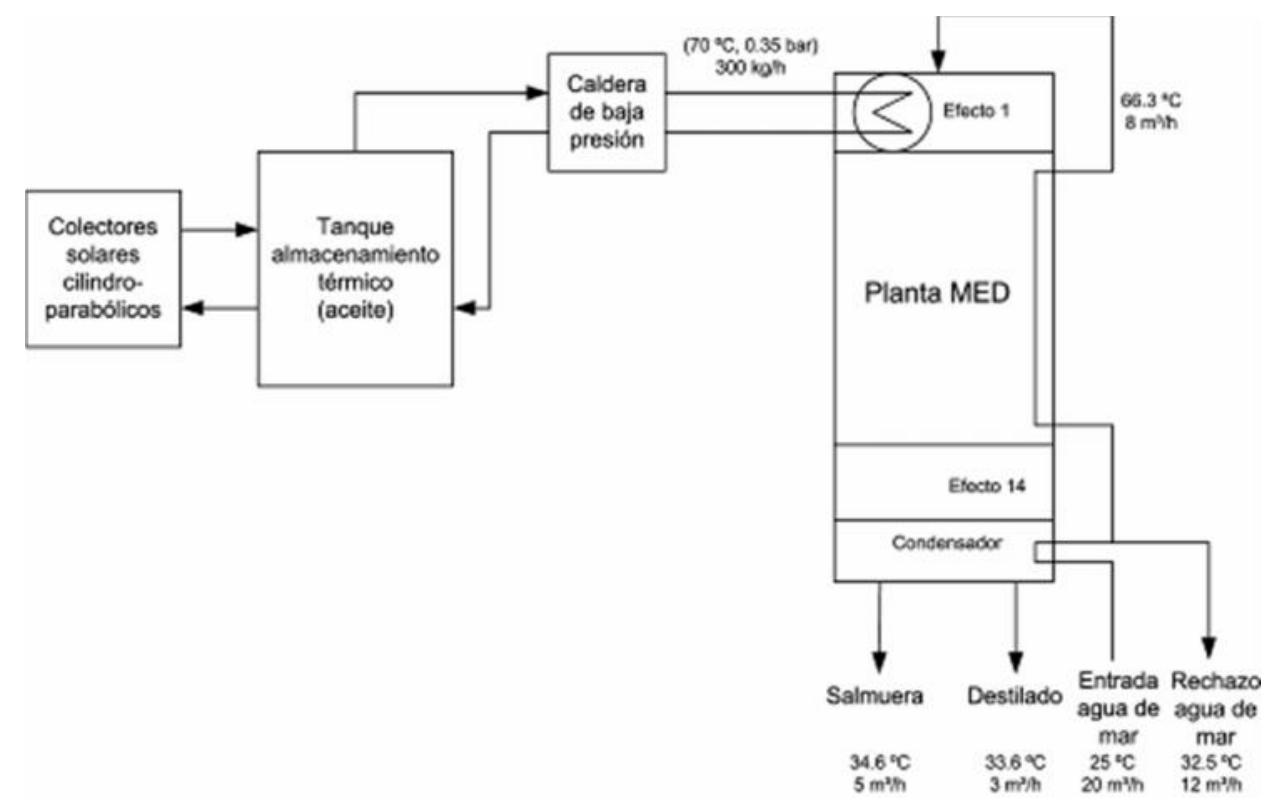

Fig. 14 Esquema del sistema solar MED instalado en la PSA durante la fase I del proyecto.

El sistema opera con aceite sintético que es calentado mientras circula a través de los colectores solares. La energía solar se convierte de esta forma en energía térmica en forma de calor sensible del aceite, y a continuación es almacenada en el tanque de almacenamiento térmico. El aceite caliente procedente del sistema de almacenamiento es el responsable de suministrar la energía térmica requerida por la planta MED. La planta desalinizadora instalada en la PSA utiliza haces de tubos horizontales sobre los que se pulveriza el agua de mar para producir su evaporación, la cual debe estar limitada a una temperatura de $70^{\circ} \mathrm{C}$ con objeto de reducir la formación de incrustaciones. La planta MED está compuesta por 14 celdas o efectos, en orden decreciente de temperatura y presión desde la celda 1 hasta la celda 14. El agua de mar es precalentada de celda en celda en los 13 precalentadores. Desde la celda 1, el agua de mar pasa de una celda a otra por efecto de la gravedad antes de ser extraída de la celda 14 mediante la bomba de salmuera. Parte del agua de mar utilizada como refrigerante del condensador es expulsada y el resto es utilizado para ser pulverizada sobre el haz de tubos de la celda 1. El agua dulce es extraída del condensador por medio de la bomba de destilado

Durante la Fase I también fue ensayada la incorporación de la compresión térmica de vapor al proceso. Para ello se aprovechó el vapor de alta presión (12-18 bar) generado para hacer funcionar una pequeña planta de electricidad que se encuentra acoplada al campo solar. Una pequeña parte de este vapor es enviada a unos termocompresores, en los cuales se mezcla con el vapor producido en la celda 14. Esta mezcla es inyectada dentro del evaporador de la primera etapa para reiniciar el proceso de desalación. De este modo se consigue que el consumo energético del proceso sea menor. 


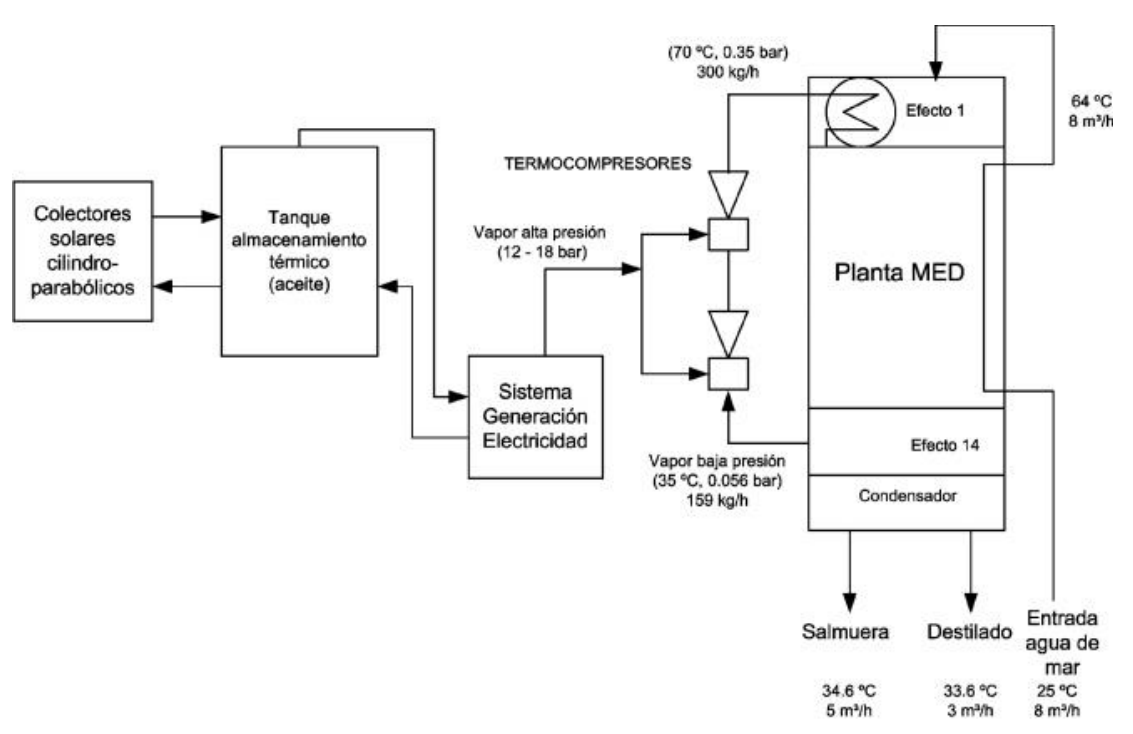

Fig.15 Esquema del sistema solar MED trabajando con termocompresores.

Para evacuar el aire de las etapas al comienzo de la operación se utiliza un sistema de vacío compuesto por dos hidroeyectores alimentados por agua de mar a 3 bar. Dicho sistema de vacío es también utilizado para compensar las pequeñas cantidades de aire y gases liberadas por el agua de alimentación y las pequeñas pérdidas producidas en las juntas.

Los resultados más notables obtenidos durante la Fase I fueron los siguientes:

- El sistema presentó una alta fiabilidad, no observándose ningún tipo de problema importante a la hora de acoplar el campo de colectores solares a la planta MED.

- Baja inercia térmica: la producción nominal de destilado se alcanzaba transcurridos 35 minutos de la puesta en marcha.

- El consumo específico de electricidad se situó en el rango que va desde los 3.3 hasta los $5 \mathrm{~kW}_{\mathrm{e}} \mathrm{h} / \mathrm{m}^{3}$ de destilado.

- La planta obtuvo un Factor de Rendimiento (número de $\mathrm{kg}$ de destilado producidos por cada $2326 \mathrm{~kJ}$ de energía suministrada) en un rango de 9.4 a 10.4 si se operaba con vapor de baja presión. Dicho rango se incrementó de 12 a 14 utilizando la termocompresión.

Como consecuencia de los resultados obtenidos durante la Fase I fue posible la identificación de potenciales mejoras que en el caso de ser implementadas podrían incrementar la eficiencia y competitividad del sistema. Las principales conclusiones de este análisis fueron las siguientes:

- El consumo eléctrico de la planta podría reducirse mediante la sustitución del sistema de vacío basado en hidroeyectores por un sistema de eyectores de vapor.

- El consumo térmico de la planta se podría reducir en un 50\% mediante la incorporación de una bomba de calor por absorción de doble efecto acoplada a la planta MED. 


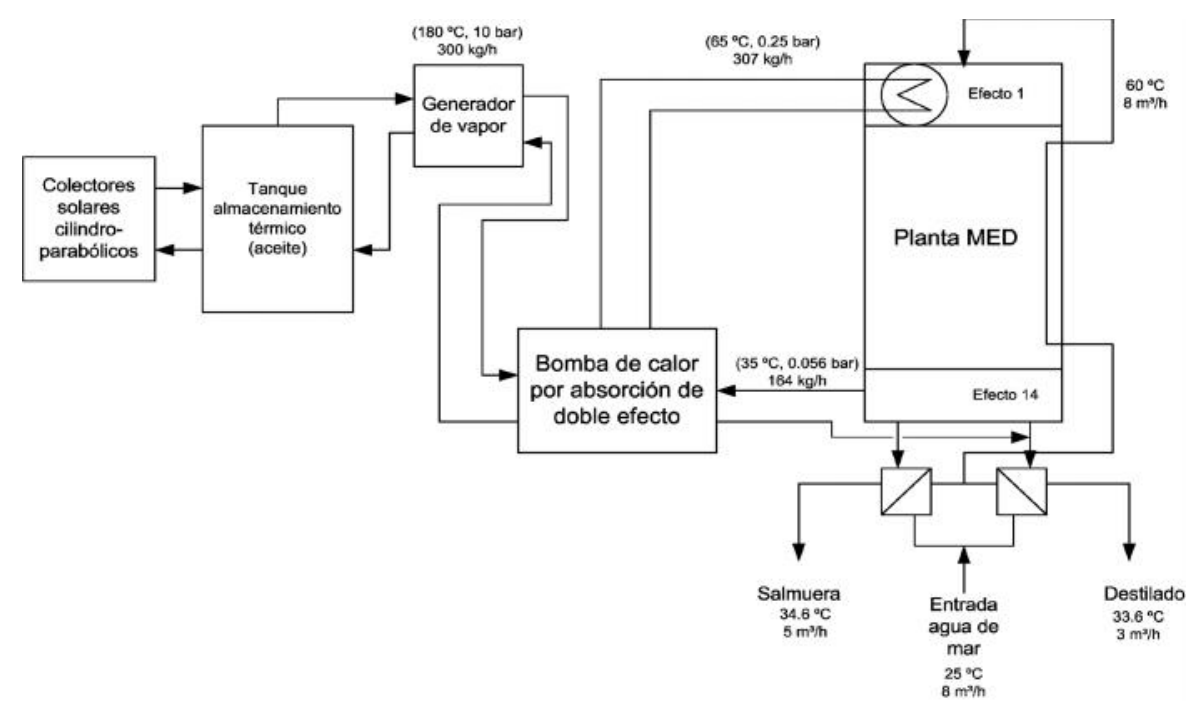

Fig. 16 Sistema solar MED mejorado (Proyecto STD - Fase II).

Puesto que las mejoras anteriormente citadas podrían reducir considerablemente el coste específico del destilado producido por el sistema, se decidió acometer la Fase II del proyecto STD. Las Figuras 16 y 17 muestran un esquema del sistema de desalación mejorado en el cual se ha acoplado una bomba de absorción de calor de doble efecto $\left(\mathrm{LiBr}-\mathrm{H}_{2} \mathrm{O}\right)$ a la planta MED. La bomba de calor es capaz de suministrar $200 \mathrm{~kW}$ de energía térmica a $65^{\circ} \mathrm{C}$ a la planta MED. El proceso de desalación en la unidad de evaporación sólo utiliza $90 \mathrm{~kW}$ de esos $200 \mathrm{~kW}$, mientras que que el resto $(110 \mathrm{~kW})$ son recuperados por el evaporador de la bomba de calor a $35^{\circ} \mathrm{C}$ y bombeados a una temperatura de operación de $65^{\circ} \mathrm{C}$. Para ello, la bomba necesita $90 \mathrm{~kW}$ de energía térmica a $180^{\circ} \mathrm{C}$. De esta manera el consumo del sistema total se redujo de $200 \mathrm{~kW}$ a $90 \mathrm{~kW}$.
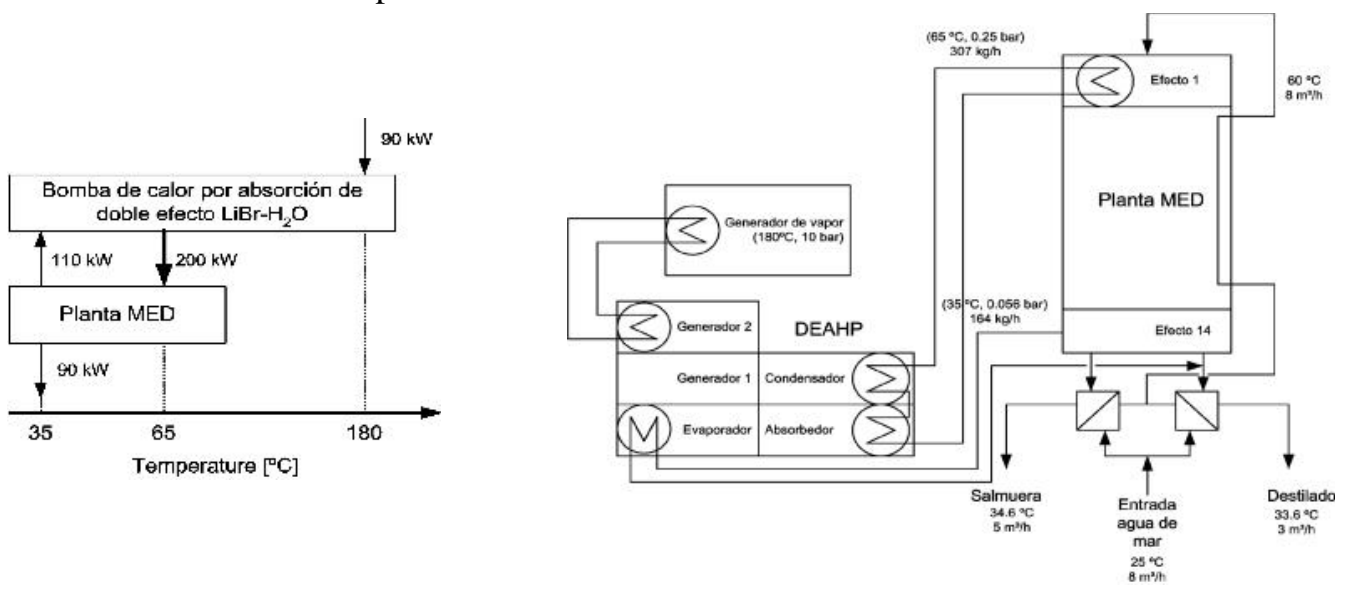

Fig. 17 Esquema conceptual de la bomba de calor por absorción de doble efecto y su acoplamiento con el sistema solar MED.

Las mejoras implementadas en el sistema desalador (bomba de absorción de calor y sistema de vacío basado en eyectores de vapor) redujeron el consumo de energía térmica en un $44 \%$, de 63 a 
$36 \mathrm{kWh} / \mathrm{m}^{3}$ (el Factor de Rendimiento aumentó hasta un valor de 20) y el consumo eléctrico en un $12 \%$, de 3.3 a $2.9 \mathrm{~kW} \mathrm{e} / \mathrm{m}^{3}$.

\section{SISTEMAS MED DE DESALACIÓN SOLAR AVANZADA: EL PROYECTO AQUASOL}

En virtud de su experiencia previa, durante el año
2001 un nuevo proyecto denominado "Enhanced Zero Discharge Seawater Desalination using Hybrid Solar Technology" (AQUASOL) fue aprobado por la Comisión Europea y sus actividades se han iniciado en el año 2002. La Tabla 6 muestra la lista de participantes en el proyecto.

Tabla 6. Lista de participantes en el proyecto AQUASOL.

\begin{tabular}{lc}
\hline \multicolumn{1}{c}{ Organización } & País \\
\hline Centro de Investigaciones Energéticas, Medioambientales y & España \\
Tecnológicas & \\
Instalaciones Inabensa S.A. & España \\
Caja Rural Intermediterránea CAJAMAR & España \\
Comunidad de Regantes las Cuatro Vegas de Almería & España \\
Instituto Nacional de Engenharia e Tecnologia Industrial & Portugal \\
AO SOL, Energias Renováveis, Lda. & Portugal \\
Hellenic Saltworks S.A. & Grecia \\
National Technical University of Athens & Grecia \\
WEIR Entropie S.A. & Francia \\
\hline
\end{tabular}

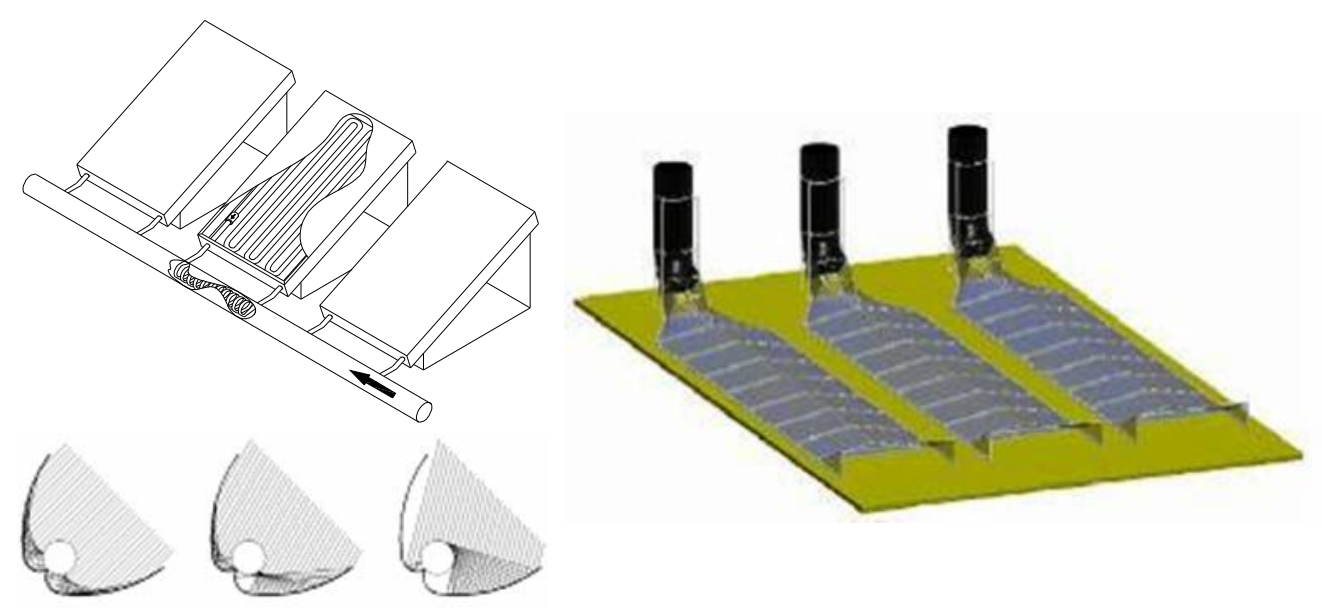

Fig. 18 Ejemplos de dos de las innovaciones tecnológicas a implementar dentro del Proyecto AQUASOL: colector solar estático (izq.) y secador solar avanzado (der.).

El proyecto está enfocado en el desarrollo tecnológico de tres aspectos fundamentales, de los cuales se espera que mejoren de manera significativa la actual eficiencia tecno-económica de los sistemas solares MED y en consecuencia se reduzca el coste de producción de agua desalada:
- Incorporación eficiente de la energía solar al proceso mediante el diseño de un sistema de colectores estáticos, del tipo CPC (Concentradores Parabólicos Compuestos), para suministrar calor a media temperatura $\left(60^{\circ} \mathrm{C}-90^{\circ} \mathrm{C}\right)$. Este sistema de colectores solares se verá 
complementado por un tanque de almacenamiento térmico de agua, y el sistema completo estará acoplado a una caldera de gas con objeto de garantizar las condiciones de operación necesarias y permitir una operación de la planta MED durante las 24 horas del día (necesario para reducir costes de capital).

- Desarrollo de una nueva Bomba de Calor por Absorción de Doble Efecto (DEAHP) optimizada y plenamente integrada dentro del proceso MED con objeto de reducir de manera significativa la energía total necesaria y mejorar la eficiencia global del proceso.

- Reducir a cero cualquier vertido del proceso mediante la recuperación de la sal contenida en la salmuera. Para ello se diseñará y desarrollará un secador solar avanzado cuyo propósito es acelerar el proceso anteriormente descrito.
La eliminación de la salmuera podría provocar una mejora adicional de la economía del proceso.

La Figura 19 muestra un diagrama conceptual del sistema propuesto. El sistema de desalación de agua de mar diseñado está compuesto de:

- Una planta de destilación multiefecto de 14 etapas.

- Un campo de captadores solares estáticos de tipo CPC (concentrador parabólico compuesto).

- Un sistema de almacenamiento térmico basado en agua.

- Una bomba de calor por absorción ( $\mathrm{LiBr}-$ $\mathrm{H}_{2} \mathrm{O}$ ) de doble efecto.

- Una caldera de gas pirotubular.

- Un secador solar avanzado para el tratamiento final de la salmuera.

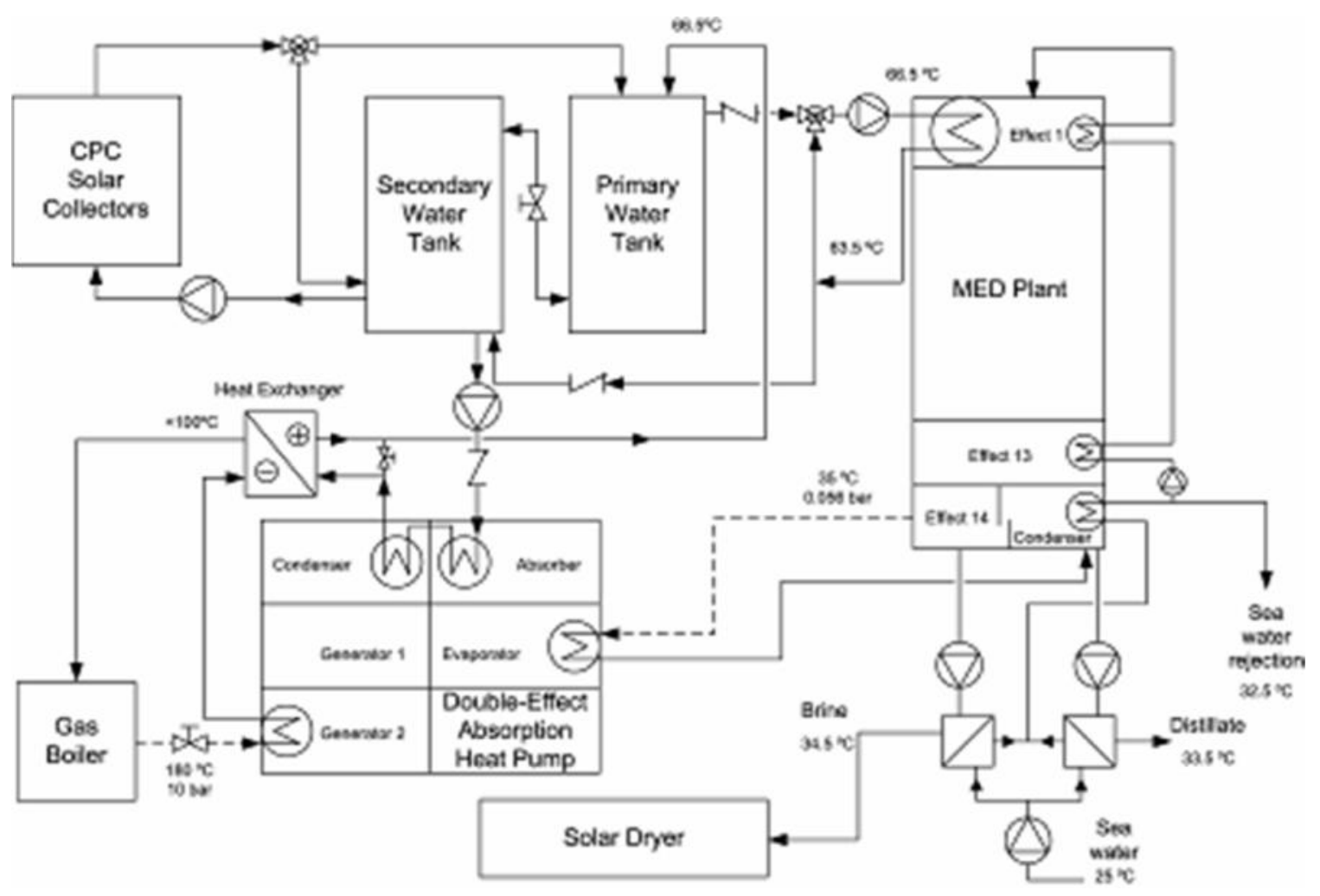

Fig. 19 Configuración del sistema de desalación propuesto en el proyecto AQUASOL.

A diferencia del Proyecto STD, este nuevo sistema opera con agua como fluido de trabajo, la cual circula a través de los captadores solares en un circuito abierto con los tanques de almacenamiento térmico. En ausencia de radiación solar, la caldera de gas alimenta una bomba de calor, la cual al 
mismo tiempo toma energía del vapor de baja exergía extraído del último efecto de la planta MED. De esa manera consigue aumentar la temperatura de retorno del primer efecto de $63.5^{\circ} \mathrm{C}$ a $66.5^{\circ} \mathrm{C}$.

\section{LA UNIDAD DE DESTILACIÓN}

La unidad de destilación es un planta de destilación multiefecto con alimentación directa y disposición vertical. La primera celda original que trabajaba con vapor saturado a baja presión $\left(70^{\circ} \mathrm{C}\right.$, 0.31 bar) ha sido sustituida dentro del Proyecto AQUASOL por un nueva, preparada para trabajar directamente con el agua caliente procedente del tanque de almacenamiento.

El lazo de recirculación del primer efecto de la planta MED se encentra regulado por un sistema de control avanzado que actúa sobre una válvula de regulación automática de tres vías. De esta manera se consigue evitar temperaturas superiores a $\operatorname{los} 70^{\circ} \mathrm{C}$ dentro del primer efecto, así como determinar la carga de operación de la bomba de calor (cuando la radiación solar disponible resulta insuficiente para alimentar la planta MED por sí sola).

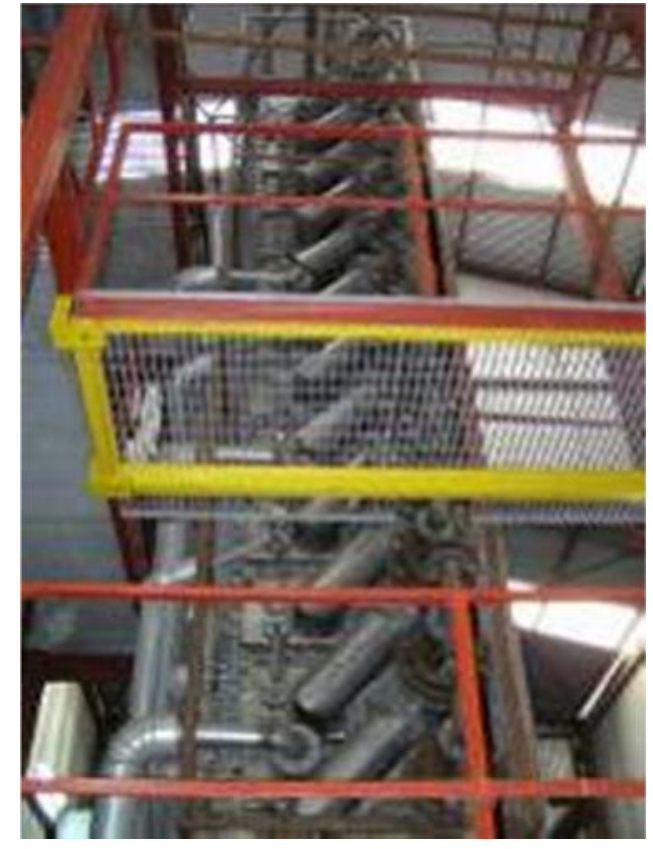

Fig. 20 Vista frontal de la planta de destilación multiefecto de la PSA.

Tabla 7. Rendimiento del nuevo primer efecto de la planta MED de la PSA.

\begin{tabular}{lll}
\hline & $\begin{array}{l}\text { Desalination driven by solar } \\
\text { collectors }\end{array}$ & $\begin{array}{l}\text { Desalination driven by } \\
\text { absorption heat pump }\end{array}$ \\
\hline $\begin{array}{l}\text { Power } \\
\begin{array}{l}\text { Inlet /Outlet hot water } \\
\text { temperature }\end{array}\end{array}$ & $200 \mathrm{~kW}$ & $150 \mathrm{~kW}$ \\
$\begin{array}{l}\text { Brine temperature (on first } \\
\text { cell) }\end{array}$ & $75.0 / 71.0^{\circ} \mathrm{C}$ & $66.5 / 63.5^{\circ} \mathrm{C}$ \\
$\begin{array}{l}\text { Hot water flow rate } \\
\text { Pressure drop }\end{array}$ & $12.0 \mathrm{~kg} / \mathrm{s}$ & $62.0^{\circ} \mathrm{C}$ \\
\hline
\end{tabular}

\section{EL CAMPO SOLAR}

El campo solar está constituido por 252 captadores solares estáticos (CPC Ao Sol 1.12x) con una superficie total de aproximadamente $500 \mathrm{~m}^{2}$, dispuestos en cuatro filas de 63 colectores.
Debido al diseño hidráulico empleado (retorno invertido) el caudal nominal total $\left(14.97 \mathrm{~m}^{3} / \mathrm{h}\right)$ de distribuye de manera uniforme entre las cuatro filas $\left(3.74 \mathrm{~m}^{3} / \mathrm{h}\right)$ sin necesidad de implementar ningún tipo de regulación adicional. 


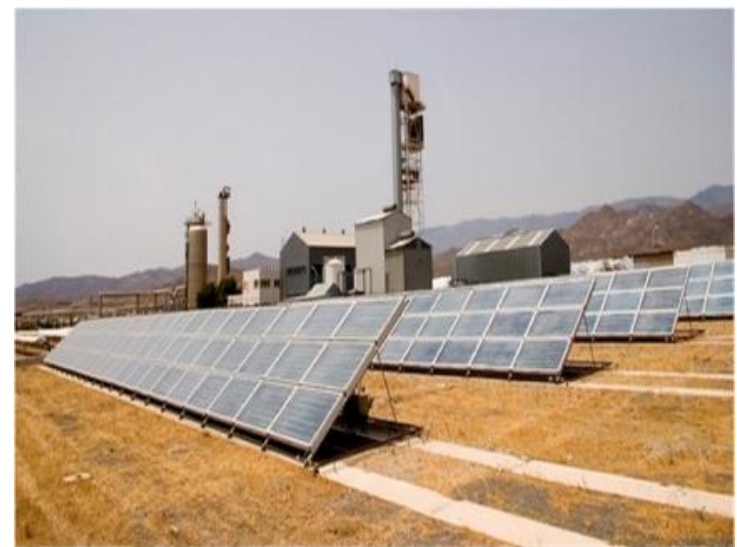

Fig. 21 Campo de captadores solares estáticos $\left(500 \mathrm{~m}^{2}\right)$ del Proyecto AQUASOL.

Los captadores se organizan en grupos de nueve, estando conectados cada uno de estos grupos en paralelo dentro de cada fila, las cuales a su vez están conectadas también en paralelo con la línea de distribución a los tanques de almacenamiento.

Cada grupo de nueve captadores se organiza de la siguiente manera: i) los captadores están orientados este-oeste con objeto de maximizar la captación de energía solar; ii) cada grupo se subdivide en tres subgrupos de tres captadores; iii) dentro de cada subgrupo los captadores están conectados en paralelo; iv) cada subgrupo se conecta con el siguiente en serie.

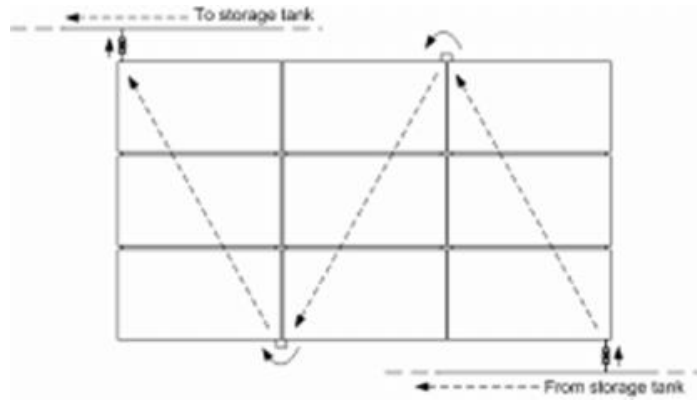

Fig. 22 Detalle de la conexión entre los captadores solares del campo AQUASOL.

Durante la fase de investigación del proyecto se ensayó la posibilidad de instalar algún tipo de material aislante (tipo honeycomb) en el interior de los captadores con objeto de reducir las pérdidas por convección. Sin embargo, debido a las temperaturas esperadas de operación (por debajo de $80^{\circ} \mathrm{C}$ ), se llegó a la conclusión de que no se obtenía una mejora justificada. Además, las temperaturas de estancamiento que se obtienen sin el material aislante son más seguras en caso de fallo de la bomba de impulsión del campo. También se consideró la utilización de un prototipo de captador CPC (1.5x) más avanzado, pero finalmente se desechó la idea ya que se producía una reducción en el número de horas que el sistema podía operar con energía solar, y realmente no se necesitaban temperaturas superiores a las que se pueden obtener con el captador de concentración 1.12.

Tabla 8. Especificaciones técnicas del captador solar AoSol 1.12x.

\begin{tabular}{ll}
\hline Dimensiones & $2012 \times 1108 \times 107 \mathrm{~mm}$ \\
\hline Area de apertura & $1.98 \mathrm{~m}^{2}$ \\
$\begin{array}{l}\text { Absorbedor (capa selectiva) } \\
\text { Emisividad }\end{array}$ & $0.10-0.15$ \\
Absorptividad & $0.94-0.95$ \\
Peso (vacío) & $38 \mathrm{~kg}$ \\
& $6 \mathrm{bar}$ \\
Presión de operación & $12 \mathrm{bar}$ \\
Presión de ensayo & $0.70-0.71$ \\
Eficiencia óptica & $3.4 \mathrm{~W} / \mathrm{m}^{2} \mathrm{~K}$ \\
& 3.5 \\
Factor de pérdidas térmicas & \\
\end{tabular}




\section{SISTEMA DE ALMACENAMIENTO TÉRMICO}

El sistema de almacenamiento térmico está formado por dos tanques de agua de $12 \mathrm{~m}^{3}$ de capacidad interconectados entre sí. El volumen final fue elegido en función del tiempo de respuesta requerido por la caldera de gas y la bomba de calor para alcanzar las condiciones nominales de operación.

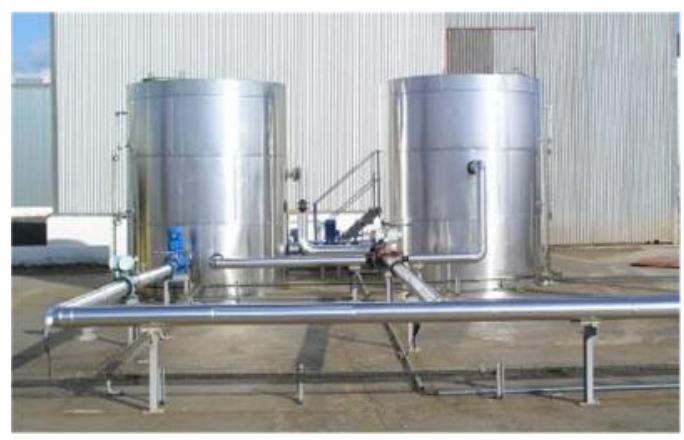

Fig. 23 Vista frontal de los tanques de
almacenamiento del proyecto
AQUASOL.

El uso de dos tanques permite aumentar la fracción solar así como obtener cierta estratificación de temperaturas necesaria para evitar que la temperatura de entrada a la bomba de calor exceda del rango permitido $\left(60^{\circ} \mathrm{C}-70^{\circ} \mathrm{C}\right)$.

\section{Caldera de gas}

Se ha instalado una caldera de gas propano como sistema de respaldo, el cual es necesario para garantizar las condiciones de operación (la bomba de calor precisa vapor saturado a $180^{\circ} \mathrm{C}$ ) y permitir una operación de la planta MED durante 24 horas (necesario para reducir la repercusión de los costes de inversión) en ausencia de radiación solar. Durante la fase de investigación del proyecto se decidió instalar una caldera pirotubular, la cual permite que la bomba de calor pueda funcionar a carga variable (entre el $30 \%$ y el $100 \%$ ).

El gas se almacena en un tanque de 2450 litros instalado junto al edificio de la planta desaladora. El tanque de retorno de condensados está a presión atmosférica, por lo que ha sido necesario instalar un intercambiador de calor que evite la evaporación súbita del condensado, transfiriendo su energía al flujo que conecta la bomba de absorción con el tanque de almacenamiento térmico.

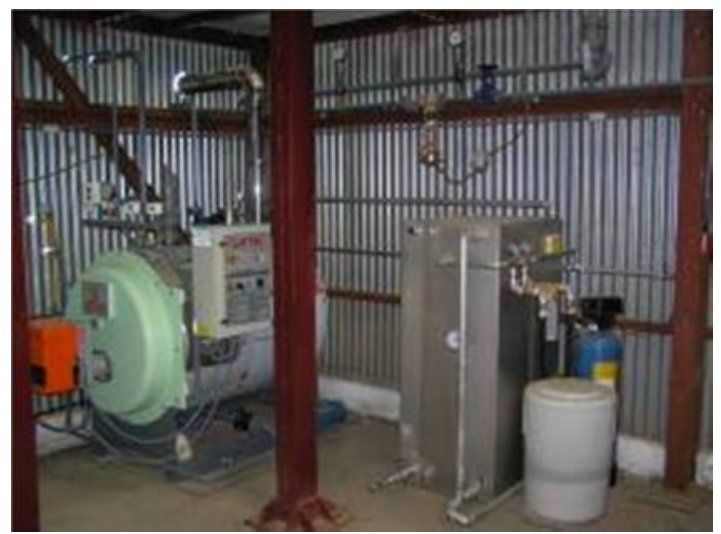

Fig. 24 Sistema de caldera de gas del Proyecto AQUASOL.

\section{BOMBA DE CALOR POR ABSORCIÓN DE DOBLE EFECTO}

La bomba de calor por absorción de doble efecto (DEAHP) instalada en la PSA (Figura 25) utiliza una solución de bromuro de litio/agua como fluido de trabajo.

Los dos circuitos por los que circula la solución fueron conectados inicialmente en paralelo, lo cual significa que la fracción másica de la solución al entrar en cada uno de los dos desorbedores es idéntica.

La configuración de flujo paralelo es más óptima desde un punto de vista termodinámico $\mathrm{y}$ de transferencia de calor, comparada con la configuración en serie, a costa de una mayor complejidad en lo que respecta al control. Sin embargo, la puesta en marcha del dispositivo puso de manifiesto la imposibilidad de conseguir la regulación óptima, por lo que finalmente fue necesario hacer las modificaciones necesarias para convertir en dispositivo en una configuración de circulación en serie. Se contemplan tres modos de operación diferentes del Sistema AQUASOL, dependiendo del origen de la energía que se suministra a la unidad de destilación: 
- Modo sólo-solar: la energía que se proporciona al primer efecto de la planta MED procede exclusivamente de la energía térmica procedente del campo solar.

- Modo sólo-fósil: la bomba de calor de doble efecto proporciona todo la energía térmica requerida por la unidad de destilación.

- Modo híbrido: la energía procede tanto de la bomba de calor como del campo solar. Se plantea el ensayo de dos filosofías de operación diferentes. En la primera de ellas, la bomba de calor opera continuamente las 24 horas al días con un $30 \%$ de contribución mínima, mientras que en la segunda opción, la bomba de calor arranca y se para dependiendo de la disponibilidad del recurso solar.

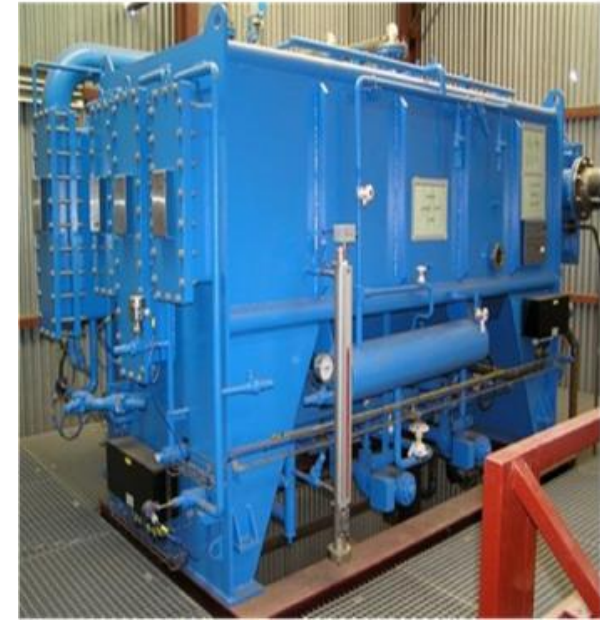

Fig. 25 Bomba de calor por absorción de doble efecto (PSA).

Tabla 9. Parámetros de diseño de la nueva DEAHP instalada en el Proyecto AQUASOL.

\begin{tabular}{llll}
\hline \multicolumn{4}{c}{ DEAHP load (\%) } \\
\hline $\mathbf{1 0 0}$ & $\mathbf{7 5}$ & $\mathbf{5 0}$ & $\mathbf{3 0}$ \\
& & & \\
& & & \\
100 & 75 & 50 & 30 \\
0.051 & 0.051 & 0.051 & 0.051 \\
35 & 35 & 35 & 35 \\
0.041 & 0.031 & 0.021 & 0.012 \\
186 & 136 & 90 & 60 \\
64 & 64 & 64 & 64 \\
67.7 & 66.7 & 65.8 & 65.2 \\
12 & 12 & 12 & 12 \\
& & & \\
82 & 62.5 & 42 & 26 \\
10 & 10 & 10 & 10 \\
180 & 180 & 180 & 180 \\
0.041 & 0.031 & 0.021 & 0.013 \\
1.22 & 1.20 & 1.18 & 1.15 \\
& & & \\
\hline & & &
\end{tabular}

La Tabla 9 muestra los parámetros de diseño de la bomba de calor operando a diferentes valores de carga. Como se puede comprobar, el coeficiente de rendimiento (COP), definido como la razón entre la potencia recuperada a baja temperatura y la potencia entregada a la bomba de calor, decrece conforme la carga de vapor decrece. 


\section{SECADOR SOLAR AVANZADO}

El objetivo del secador solar avanzado es incrementar la concentración de la salmuera hasta que alcance el punto de saturación del carbonato cálcico $\left(16^{\circ} \mathrm{Be}\right.$, escala Baumé). Durante el Proyecto AQUASOL se han evaluado diferentes prototipos, hasta llegar a un diseño final considerado el más óptimo. Éste ha consistido en una serie de tres canales de evaporación paralelos (4 m x $17 \mathrm{~m}$ ) interconectados entre sí, a través de los cuales circula la salmuera. Los canales de evaporación están dotados de una cubierta de plástico, una sección de precalentamiento a la entrada del canal y una chimenea solar localizada a la salida, la cual tiene como objeto promover la circulación del aire a través de los canales. Se prevé que estos diseños puedan suponer un aumento de más del doble comparado con la eficiencia de un estanque salino tradicional a cielo abierto

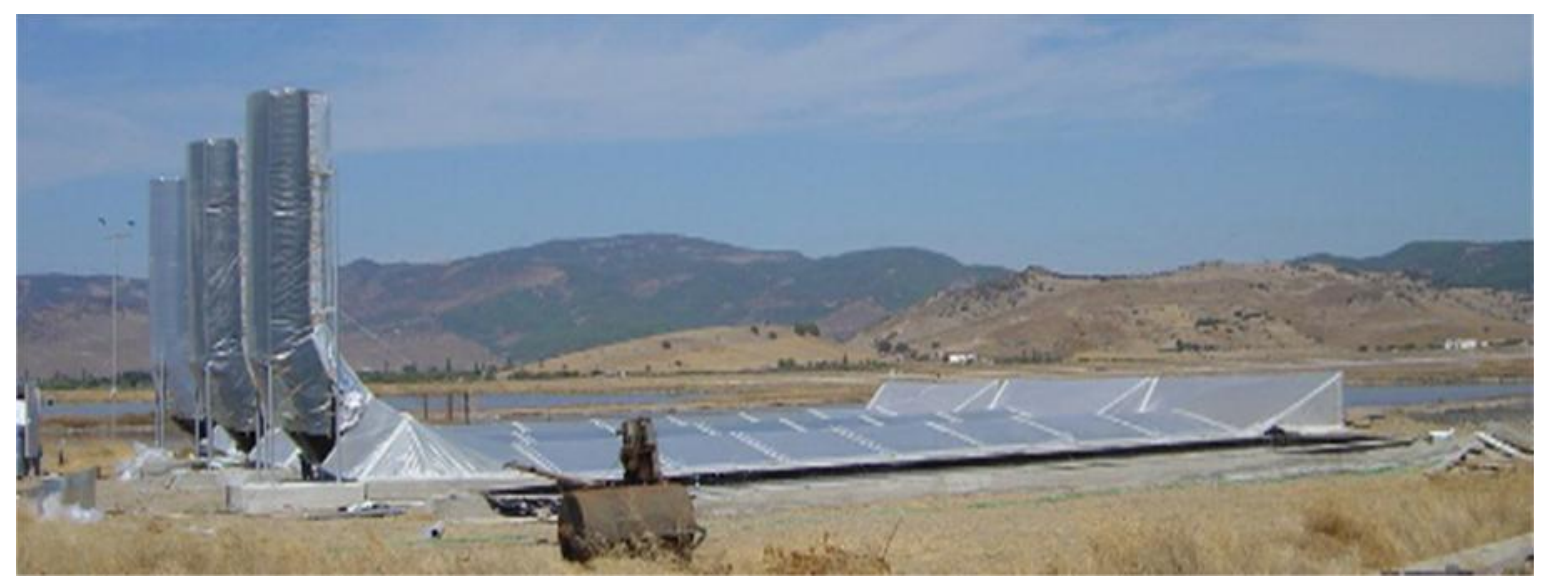

Fig. 26 Secador solar avanzado del Proyecto AQUASOL.

\section{LOS COSTES DE LA DESALACIÓN}

A finales del año 2004 tuvo lugar en Chipre una conferencia internacional en la que se dieron cita todos los expertos mundiales en desalación. El objetivo de esta conferencia fue clarificar de una vez por todas cuáles eran los costes asociados a la desalación. La conclusión de dicho evento fue la esperada: resulta prácticamente imposible establecer un criterio que permita determinar dicho coste, ya que el número de variables que afectan al cálculo del mismo es muy grande.

Muchos de los costes asociados a la desalación, en particular los costes energéticos, presentan una variación importante en función del tiempo, localización geográfica $\mathrm{y}$, en el caso de las tecnologías de membranas, de la concentración del agua de alimentación. Además hay que tener en cuenta que la composición química del agua de alimentación determina un determinado grado de pretratamiento y por lo tanto también influye en el coste. La capacidad total de la planta juega a su vez un papel importante a la hora de determinar el coste del agua producto.

Una complicación adicional viene dada por el hecho de que no existe un procedimiento estandarizado a la hora de realizar dicho cálculo, y nos podemos encontrar que muchos autores no tienen en cuenta la amortización de los costes de inversión, otros incluyen en sus cálculos hasta los costes de distribución, e incluso podemos encontrar otros trabajos en los que no se tiene en cuenta los costes de operación.

Wade (2001) llevó a cabo una comparación de los costes de producción de agua mediante procesos de destilación térmica (MSF, MED) y ósmosis inversa (RO, RO+Brine Booster). Para ello, llevó a cabo un estudio de cuatro plantas con la misma capacidad de desalación $(31.822 \mathrm{~m} 3 /$ día), operando en el área mediterránea y con un coste de combustible de $1.7 € /$ GJ. Los resultados se muestran en la Tabla 10. 
Tabla 10. Estimación de costes de agua de mar desalada con diferentes tecnologías convencionales (Wade, 2001).

\begin{tabular}{cc}
\hline MSF & $1.18 € / \mathrm{m}^{3}$ \\
MED & $1.08 € / \mathrm{m}^{3}$ \\
RO & $0.93 € / \mathrm{m}^{3}$ \\
RO + bomba booster & $0.85 € / \mathrm{m}^{3}$ \\
\hline
\end{tabular}

Otros trabajo interesante es el de Semiat, que añade al trabajo anterior el análisis de costes las tecnologías de compresión mecánica de vapor y ósmosis inversa de aguas salobres (Tabla 11).

Tabla 11. Estimación de costes de desalación con diferentes tecnologías convencionales (Semiat, 2000).

\begin{tabular}{cc}
\hline MSF & $1.10-1.50 € / \mathrm{m}^{3}$ \\
MED & $0.46-0.85 € / \mathrm{m}^{3}$ \\
MVC & $0.87-0.92 € / \mathrm{m}^{3}$ \\
OI (Agua de mar) & $0.45-0.92 € / \mathrm{m}^{3}$ \\
OI (Agua salobre) & $0.20-0.35 € / \mathrm{m}^{3}$ \\
\hline
\end{tabular}

En lo que se refiere a ósmosis inversa de agua de mar, la Tabla 15 muestra los precios de agua para los proyectos BOOT (Build, Own, Operate and Transfer) más recientes:

Tabla 12. Análisis comparativo de los proyecto BOOT más recientes en ósmosis inversa.

\begin{tabular}{lcccccc}
\hline & $\begin{array}{l}\text { Tampa } \\
\text { Bay }\end{array}$ & Trinidad & Larnaca & Dhekelia & Singapore & Ashkelon \\
\hline $\begin{array}{l}\text { Capacidad, } \\
\mathrm{m}^{3} / \mathrm{d}\end{array}$ & 95000 & 135000 & 40000 & 40000 & 136000 & 330000 \\
$\begin{array}{l}\text { Salinidad, } \\
\text { ppm }\end{array}$ & 26000 & 38000 & 40000 & 40000 & - & 40000 \\
$\begin{array}{l}\text { Precio } \\
\text { agua, }\end{array}$ & 0.46 & 0.71 & 0.73 & 1.09 & 0.45 & 0.52 \\
$\mathrm{US} \$ \mathrm{~m}^{3}$ & & & & & & \\
\hline
\end{tabular}



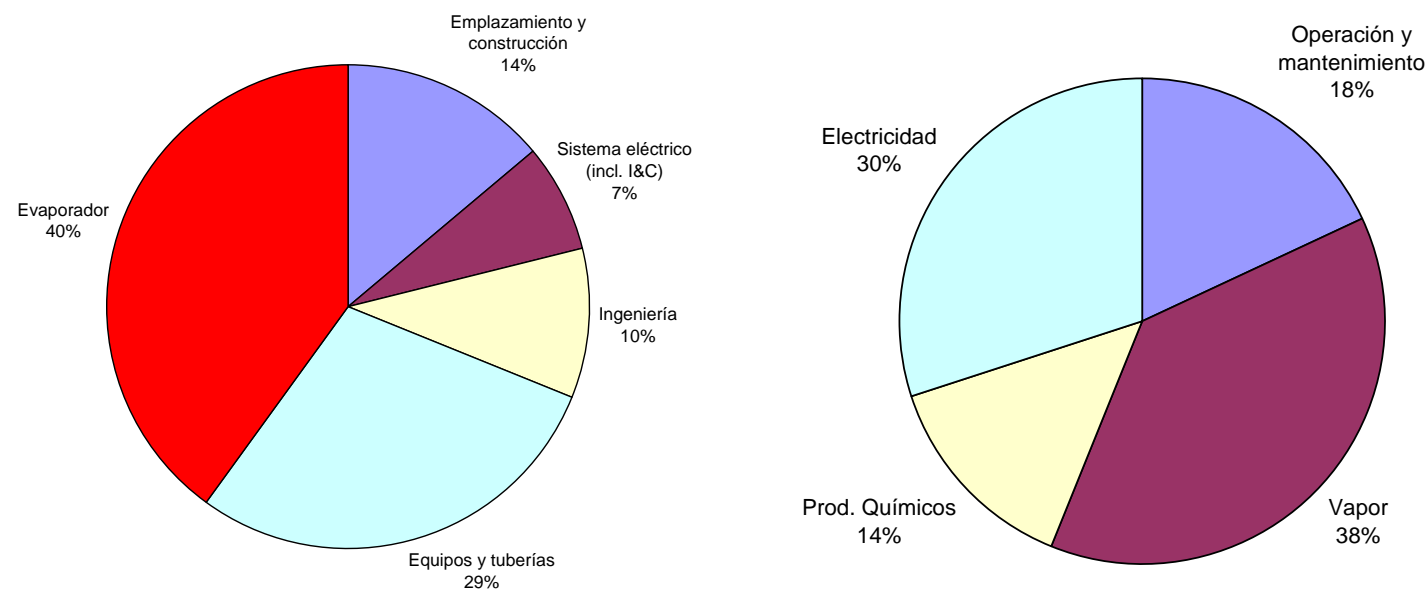

Fig. 27 Desglose de los costes de inversión (izq.) y de operación (der.) de una planta de destilación térmica.

En general los costes de inversión suponen aproximadamente un $40 \%$ del coste final del producto, mientras que los costes de operación tienen una contribución del $60 \%$ restante. Esto es más o menos independiente de si se trata de una planta de destilación térmica (MSF, MED) o una planta de ósmosis inversa para agua de mar. En el caso de ósmosis de aguas salobres, la repercusión del coste de inversión sobre el coste final del agua producto puede llegar hasta un $54 \%$.

En la Figura 27 se muestra un desglose de los costes de inversión y los costes de operación de una planta de destilación térmica en general. En lo que se refiere a los costes de inversión, podemos observar que las superficies de intercambio de calor tienen la mayor contribución, y por tanto los esfuerzos de investigación y desarrollo deberían centrarse en intentar minimizar en lo posible dicha área dentro de estos procesos. En cuanto a los costes de operación, el suministro de vapor supone la principal componente, por lo que si se consigue disminuir su contribución, se puede conseguir una reducción notable en el coste final.

Por ello, en Oriente Medio, la mayor parte de las plantas de destilación se encuentran acopladas a una planta de generación de electricidad, de modo que puedan aprovechar las primeras el vapor de baja energía procedente de la turbina. 


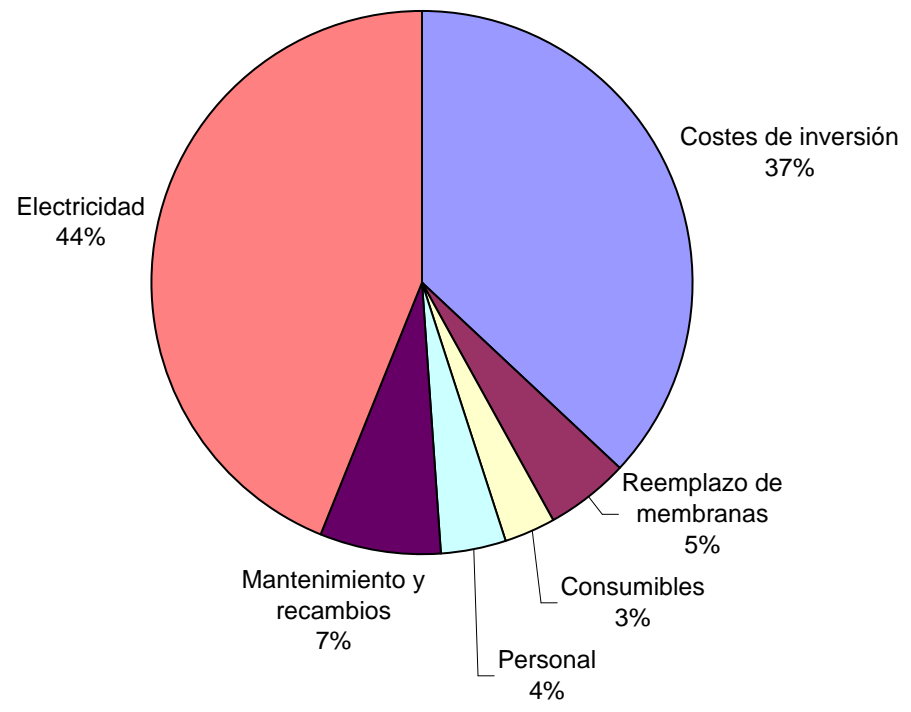

Fig. 28 Desglose del coste de agua producto para una planta de ósmosis inversa de agua de mar.

La Figura 28 muestra un desglose del coste final del agua producto en una planta de desalación de agua de mar por ósmosis inversa. Como puede observase las principales contribuciones provienen de la amortización de los coste de inversión (37\%) y el consumo de electricidad (44\%).

En una planta de ósmosis para aguas salobres los costes de inversión tienen una repercusión del 54\% mientras que el consumo eléctrico sólo del $11 \%$ debido a la menor salinidad del agua a tratar.

Por lo tanto, se deduce que en el caso de plantas de ósmosis inversa para agua de mar es necesario hacer un especial énfasis en los sistemas de recuperación de energía con objeto de abaratar el coste final del agua desalada.

\section{¿ES POSIBLE EL DESARROLLO SUSTENTABLE EN EL SIGLO XXI?}

Es evidente que cuando a alguien le preguntan qué tipo de desarrollo prefiere, si sustentable o no sustentable, salvo error u omisión, la práctica totalidad responderá que el primero. Sin embargo, la realidad es tozuda y, también en la mayoría de los casos, acaban primando los condicionantes económicos.

La pregunta real que debemos hacernos no es tanto ¿cuál debe ser la política para resolver los problemas medioambientales y energéticos?, sino ¿qué combinación de beneficios, coste y riesgo queremos aceptar? Y, en mi opinión, el cómo y el cuándo se resuelva esta cuestión es algo vital y urgente ya que afectará tanto a nuestras vidas como al medioambiente $\mathrm{y}$, por ende, a las generaciones futuras.

Para ilustrar mejor este concepto de desarrollo sustentable o sostenible, considero muy ilustrativo el ejemplo de los desarrollos económicos que han tenido lugar en Almería durante los siglos XIX y $\mathrm{XX}$. Creo que las conclusiones que esta historia nos ofrece son fácilmente extrapolables a muchos otros entornos tanto locales como globales.

\section{Siglo XIX: desarrollo de la actividad minera en Almería}

La provincia de Almería siempre ha sido reconocida como una zona con un gran potencial minero debido a la existencia en ella de una gran cantidad de minerales.

Esta actividad minera, que siempre ha existido, ya estaba presente en la provincia a comienzos del Siglo XIX. Sin embargo, en 1838 se descubrió un importante yacimiento de plomo argentífero en Sierra Almagrera, que fue reconocido en su momento como el más importante del mundo. 
Este yacimiento tuvo un valor muy importante no sólo económico sino también estratégico ya que el plomo era un mineral muy valorado militarmente en aquella época, ello dio lugar a que las principales empresas mineras de la época, a nivel mundial, se desplazaran a Almería para su explotación.

Como resultado de ello, otros muchos otros yacimientos significativos fueron encontrados: hierro, zinc, azufre, cobre, oro, etc.

La consecuencia fue la aparición de una auténtica "fiebre minera" en la región que dio lugar a un notable incremento de la actividad económica y, consecuentemente, de la población (inmigración). Para mediados de siglo, Almería era ya claramente el centro mundial de la actividad minera.

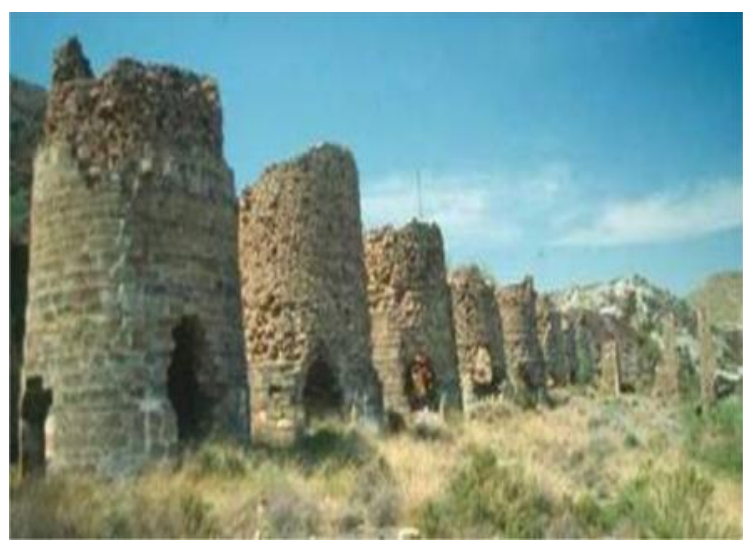

Fig. 29 Restos de hornos industriales de la industria minera del S. XIX en Almería.

La actividad de extracción del plomo (la más importante a mediados del Siglo XIX) se caracterizó por multitud de pequeñas compañías mineras con rudimentarias instalaciones y métodos de trabajo, El mineral era fundido in situ para producir barras de mineral, utilizando combustible vegetal (única posibilidad existente). En 1748 existían casi 11 millones de árboles en la provincia de Almería (inventariados a raíz de la R.O. de Montes), que desaparecieron en un porcentaje altísimo como consecuencia de dicha actividad minera. Cuando estos empezaron a escasear y el coste de la madera era considerado elevado, se utilizó el esparto, que era también muy abundante en el entorno. Para mediados del Siglo XIX, alrededor de 1.4 millones de Tm de esparto y 52.000 Tm de carbón vegetal fueron consumidos contribuyendo significativamente a un proceso de deforestación masiva en la provincia, como consecuencia de la destrucción de la cubierta vegetal (ejemplo más importante de desertificación existente en Europa). Una vez el combustible vegetal empezó a escasear, la mayoría de las pequeñas instalaciones desaparecieron y el modelo económico comenzó a colapsar. Sin embargo, el daño medioambiental ya estaba hecho: el proceso de degradación continuó, afectando la actividad tradicional de agricultura y ganadería. En la segunda mitad del Siglo XIX, grandes compañías reemplazaron el modelo de las pequeñas instalaciones mineras. Grandes instalaciones industriales basadas en carbón mineral fueron construidas (Figura 29). Simultáneamente, el valor de mercado de todos los metales sufrió una continua caída (desde 1861 a 1894 el valor del plomo cayó un $61 \%$ ). Aunque el ferrocarril acabó llegando en 1895, toda la actividad colapsó finalmente en 1910.

La provincia sufrió una terrible depresión económica con la consecuencia de una intensa emigración, principalmente a Europa y Sudamérica ante la inexistencia de alternativas económicas dadas sus condiciones extremadamente desfavorables para el desarrollo:

- Muy escasas precipitaciones (nivel de desierto, inferiores a $200 \mathrm{~mm} / \mathrm{año}$ ).

- Superficie muy montañosa (mayor desnivel medio de toda la península Ibérica).

- Situación periférica tanto en España como en Europa.

- Inexistencia de recursos naturales.

Como puede apreciarse en la Figura 30, la provincia del Almería sufrió una fuerte emigración desde 1900 hasta 1970, manteniéndose prácticamente constante la población de 1900 (366.000 habitantes). 


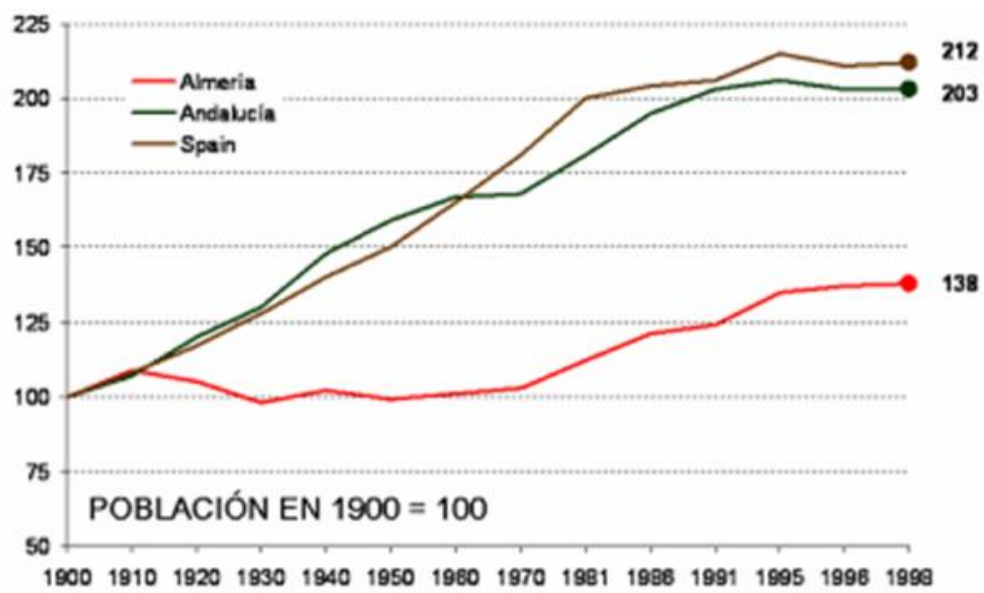

Fig. 30 Evolución relativa demográfica a lo largo del $S$. XX.

\section{Siglo XX: desarrollo de la agricultura intensiva bajo plástico en Almería}

A mediados de los años 60 , la principal actividad económica en la provincia de Almería era la misma que 150 años atrás, antes del desarrollo de la minería: la agricultura. Sin embargo, en 1963, un ingeniero propuso en Almería la posibilidad de usar el concepto de invernadero de plástico para mejorar la eficiencia en el cultivo de hortalizas. A partir de ahí, un nuevo milagro económico se ha producido, siendo Almería el centro mundial de una actividad como es la de la agricultura intensiva bajo plástico, que ha ido creciendo continuamente en la provincia (Figura 31). En el año 2000, había unas 25,000 hectáreas de superficie invernada en
Almería, mientras que en la totalidad del área Mediterránea había 130.000 ha y unas 450.000 ha en todo el mundo. Esta actividad es responsable de más del $40 \%$ del producto interior bruto de la provincia y ha supuesto una dinamización total de la economía, con un crecimiento sostenido entre los más altos del estado durante los últimos 20 años. Algunos datos son los siguientes:

- 25.000 hectáreas.

- 12.015 explotaciones $(2,1$ hectáreas/exploitación / 39.500 trabajadores).

- $36 \%$ de agricultores < 35 años.

- 115 organizaciones comercializadoras (8.500 trabajadores).

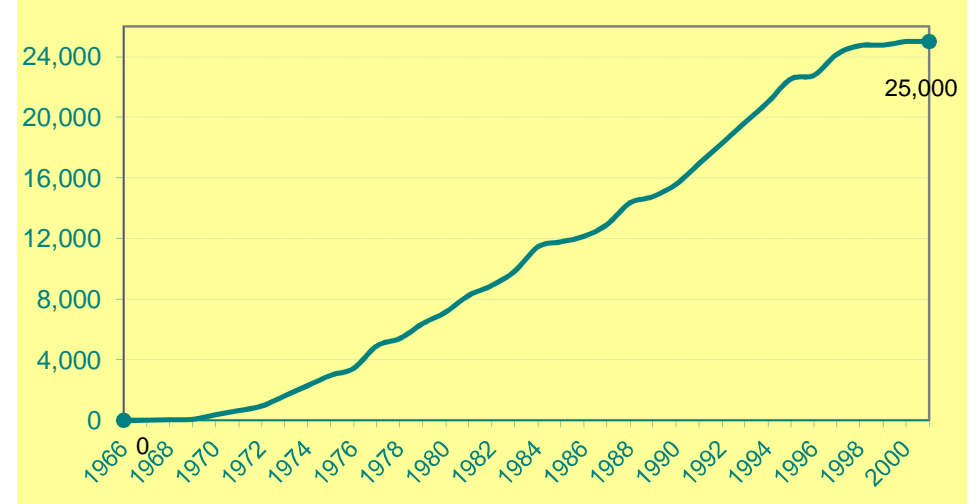

Fig. 31 Evolución de la superficie invernada bajo plástico en la provincia de Almería.

Sin embargo, toda esta actividad, al igual que ocurrió en un principio con la minería, depende de un modo fundamental de un recurso natural existente. Antes era la madera y ahora es el agua. Debido precisamente al proceso de desertización (Figura 32) ocurrido como consecuencia de la 
anterior actividad, el agua es ahora un recurso escaso y tremendamente sobreexplotado.

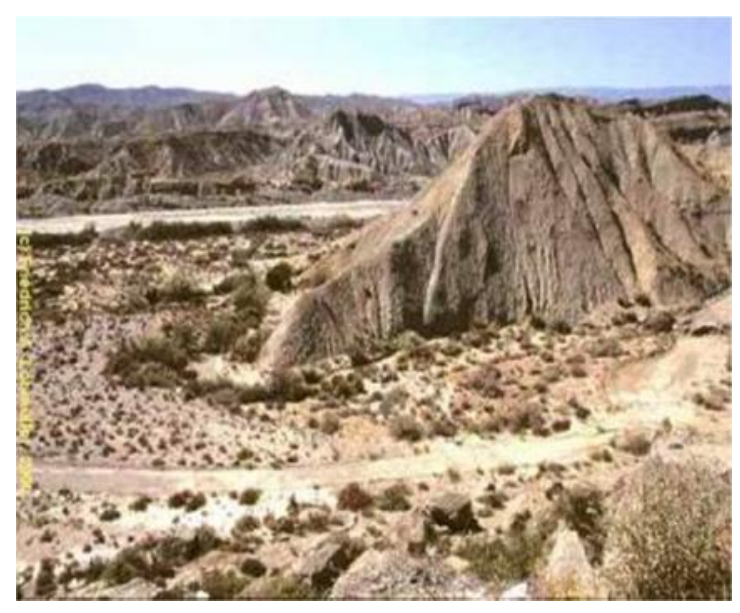

Fig. 32 Desertización en la provincia de Almería. Ejemplo de cauce seco (rambla).

Esta actividad económica demanda cada vez más agua, excediendo con mucho los recursos renovables existentes (filtraciones a los acuíferos desde Sierra Nevada, Granada).

Dado que los acuíferos (recurso fósil) constituyen la única fuente de agua existente en Almería, su sobreexplotación (Tabla 12) está causando un descenso del nivel freático y una salinización de los acuíferos debido a la cada vez mayor intrusión salina.

Tabla 12. Balance Hídrico en la provincia de Almería. Datos en $\mathrm{Hm}^{3}$ /año.

\begin{tabular}{llcc}
\hline & $\mathbf{1 9 9 2}$ & $\mathbf{1 9 9 7}$ & $\mathbf{2 0 0 2}$ \\
\hline Oferta & 240 & 240 & 240 \\
Demanda & 512 & 531 & 550 \\
Balance & -272 & -291 & -310 \\
\hline
\end{tabular}

Si no se hace nada para remediarlo, el agotamiento del recurso natural base no sólo puede acabar con esta actividad económica sino que, de nuevo, puede claramente suponer una hipoteca considerable para las futuras generaciones. Claramente, este desarrollo no es sostenible y los beneficios a corto plazo, como ya se demostró 100 años antes, de ninguna manera pueden compensar los perjuicios potenciales que pudieran tener lugar.

Otros ejemplos de desarrollos no sostenibles en el Siglo XX:

- En los años 20, el químico americano Thomas Midgley desarrolló un procedimiento para incrementar la eficiencia de los motores de gasolina mediante la adición de plomo. El método fue globalmente adoptado hasta su abandono a finales del siglo XX (tras haber vertido a la atmósfera enormes cantidades de contaminantes altamente tóxicos).

- El mismo químico, Midgley, también descubrió el Freon (el primer CFCs), compuesto que fue entusiásticamente usado como refrigerante y propelente. $\mathrm{Su}$ producción fue también abandonada a finales de la década de los 80 debido a su efecto dañino sobre la capa de ozono.

\section{CONCLUSIONES}

Todas las fuentes de energía de nuestro planeta tienen su origen en el Sol, existiendo en la actualidad un consenso respecto a la necesidad de reemplazar, a medio y largo plazo, el suministro de energías fósiles que se originaron hace millones de años y que hoy solo se consumen, por otras fuentes de energía renovables. Aunque este es un objetivo a medio y largo plazo, la creciente preocupación medioambiental está imponiendo el concepto de desarrollo sostenible y, a la vez, el desarrollo global de sistemas energéticos sostenibles será muy difícil sin una participación sustancial de las fuentes de energías renovables. La energía solar es la más abundante, uniforme y disponible de todas las fuentes de energía renovables: la energía solar recibida por la Tierra cada diez días es equivalente a todas las reservas conocidas de petróleo, carbón y gas. Los procesos y tecnologías medioambientales de la energía solar cubren un amplio rango de aplicaciones que complementan la más inmediata de producción de energía y electricidad. La problemática del agua en particular es una de las más importantes a la que se va a enfrentar la humanidad en el Siglo XXI (según palabras de Federico Mayor Zaragoza, "las problemáticas más importantes de la humanidad en este Siglo van a ser 3: agua, energía y paz, y todas ellas están interrelacionadas"), sin olvidar la 
medioambiental. Las soluciones que se planteen, ya de por sí difíciles y complicadas, deben, además, incorporar otro factor que todavía las dificulta aún más: deben ser sostenibles.

Es en este escenario en el que las energías renovables en general y la energía solar, con un grado de madurez ya más que suficiente en muchos casos, no sólo pueden y deben sino que, inevitablemente, tendrán que jugar un papel fundamental en la solución de esta compleja problemática global. Una opinión ampliamente extendida es la de que, "si las energías renovables no son una solución global inmediata es a causa de los obstáculos políticos, entre otros, con que aún tropiezan, pero no por razones tecnológicas; su despegue definitivo depende de que los poderes públicos creen mejores condiciones para favorecer este mercado, al igual que hicieron en su día para propiciar la preeminencia del petróleo o la energía nuclear".

No se puede obviar que existen también importantes barreras económicas para este desarrollo. Las energías renovables son, todas ellas, muy intensivas en capital, requiriendo unos plazos de amortización muy largos, muchas veces incompatibles con unos mercados cada vez más volátiles e inciertos, que exigen amortizaciones a corto plazo. Además, se ha de tener en cuenta que, en la mayoría de los casos, las energías renovables jamás van a alcanzar un nivel de costes inferior al que hemos disfrutado con las denominadas energías convencionales. La razón para ello es muy simple: las energías renovables poseen un valor añadido muy importante que las otras no tienen, que es el de la sostenibilidad. Este valor añadido es el que hace que el coste no pueda, ni deba, ser el mismo. En este sentido, los beneficios de las energías renovables son su escaso impacto en el medioambiente, beneficio que no se puede traducir económicamente debido a que el hecho contrario no grava las energías convencionales. Al final, como se indicaba anteriormente, nuestra sociedad debe tomar urgentemente el compromiso entre beneficios, costes y riesgos que se quieren o se pueden asumir.

\section{REFERENCIAS}

1. Ajona, J. I., (1992) "Desalination with Thermal Solar Systems: Technology
Assessment and Perspectives". CIEMAT, Madrid.

2. Buros, O. K., (2000) “The ABC's of Desalting. International Desalination Association, Topsfield", Massachusetts.

3. Delyannis, E., (2003) "Historic background of desalination and renewable energies". Solar Energy 75, 357-366.

4. El-Dessouky, H. T., Ettouney, H. M., (2002) "Fundamentals of Salt Water Desalination". Elsevier, Amsterdam.

5. Ettouney, H., (2005) "Design and analysis of humidification dehumidification desalination process".

6. Fariñas Iglesias, M., (1999) "Ósmosis Inversa. Fundamentos, Tecnología y Aplicaciones". McGraw Hill, Aravaca, Spain.

7. García-Rodríguez, L., (2002) "Seawater desalination driven by renewable energies: a review. Desalination" 143, 103-113.

8. García-Rodríguez, L., (2003) "Renewable energy applications in desalination: state of the art. Solar Energy" 75, 381-393.

9. Hoffer, et al., Nature 395, 883, 1998. "Howard G. and Bartram J. (2003) Domestic Water Quantity, Service Level and Health". World Health Organization, Geneva.

10. Ibrahim Perera, J. C., (1998) "Desalación de Aguas". Colegio de Ingenieros de Caminos, Canales y Puertos. Madrid.

11. Koschikowski, J., et al. (2002) "Solar thermal driven desalination plants based on membrane distillation". Proceedings of Membranes in Drinking and Industrial Water Production Congress, Mülheim 22-26 September 2002.

12. Medina, J. A., (2000) "Desalación de Aguas Salobres y de Mar. Ósmosis Inversa". Ediciones Mundi-Prensa, Madrid.

13. Miller J. E. (2003) "Review of Water Resources and Desalination Technologies". Report SAND 2003-0800, Sandia National Laboratories, Albuquerque, NM, USA.

14. Rizzuti, L., Ettouney, H., (2006) "Solar desalination: a challenge for sustainable fresh water in the 21st century". NATO ARW "Solar Desalination for the 21st Century", Hammamet (Tunisia), February 23th-25th 2006.

15. Semiat, A. R., (2000) "Water International" 25 , p. 54.

16. Shiklomanov, I. A., (1998) "World Water Resources". A New Appraisal and 
Assessment for the 21st Century. UNESCO Publishing, Paris.

17. Spiegler, K.S., El-Sayed, Y. M., (1994) “A Desalination Primer. Balaban Desalination Publications", Santa Maria Imbaro, Italy.

18. United Nations (2003) "Water for People, Water for Life" - UN World Water Development Report. UNESCO Publishing, Paris Valero et al. (2001) La Desalación como Alternativa al Plan Hidrológico Nacional. CIRCE, http://circe.cps.unizar.es

19. Valero., et al. (2001) "La Desalación como Alternativa al Plan Hidrológico Nacional". CIRCE, http://circe.cps.unizar.es

20. Veza, J. M., (2002) "Introducción a la Desalación de Aguas". Servicio de Publicaciones de la Universidad de Las Palmas de Gran Canaria.

21. Wade, N. M., (2001) "Distillation plant development and cost update". Desalination 136, 3-12.

22. Wangnick, K., (2002) 2002 "IDA Worldwide Desalting Plants Inventory”. Report No. 17.
Wangnick Consulting, Gnarrenburg.

23. Wermey, J. W., (2003) "Taweelah-A1 makes breakthrough in large-scale MED plants". Desalination \& Water Reuse Vol. 12(4), 9-13.

24. Wesson, W., (2004) "Los intercambiadores de presión PX de ERI: el sistema de cámaras isobáricas de recuperación de energía más fiable y extendido en el mundo". Jornadas Nacionales sobre Desalación, Madrid 17-18 Noviembre 2004.

25. Wiseman, R., (2004) "Desalination business stabilised on a high level" - IDA Report. Desalination \& Water Reuse Vol. 14(2), pp. 14-17

26. Zarza, E., (1991) "Solar Thermal Desalination Project". First Phase Results \& Second Phase Description. Editorial Ciemat, Madrid.

27. Zarza, E., (1994) "Solar Thermal Desalination Project. Phase II Results \& Final Project Report". Editorial Ciemat, Madrid.

Correspondencia: julian.blanco@psa.es 